Trabajo seleccionado para su publicación por el jurado del Premio Estudios Financieros, formado por: don José Ignacio Baile Ayensa, don Julio Cabero Almenara, doña Trinidad Manzano Moreno, don Antonio Pastor Sanmillán, don Juan Pazos Sierra y don Ismael Sanz Labrador.

\title{
Herramientas tecnológicas para la educación inclusiva
}

\section{Extracto:}

Dentro de las posibilidades que la incorporación de las tecnologías de la información y la comunicación (TIC) ofrece a la educación se encuentra la atención a la diversidad, ya que por medio de estas herramientas se puede facilitar el acceso y la educación de calidad a los estudiantes con diversas necesidades educativas especiales. Existen diferentes tipos de discapacidad (las discapacidades motrices, las sensoriales [entre las que podemos encontrar la visual y la auditiva] y las intelectuales) con muchos tipos diversos de manifestaciones. Los estudiantes con estos tipos de discapacidad se enfrentan a la dificultad de acceder a la educación de forma igualitaria. A pesar de que se han venido logrando avances en cuanto a su integración, se deben incrementar los esfuerzos para conseguirla en su totalidad.

Por este motivo, la meta del presente trabajo es hacer un repositorio de herramientas tecnológicas y actividades didácticas para cada tipo de discapacidad y presentar un programa pedagógico para la aplicación de las mismas en casos concretos que nos permita utilizar las nuevas tecnologías al servicio de la integración de los alumnos con discapacidad. Para lograr esta meta se ha llevado a cabo un estudio empírico de tipo cualitativo-descriptivo en el que se presenta un repositorio de las principales aplicaciones existentes para el trabajo con alumnos de diversas discapacidades, analizando sus ventajas y desventajas. La metodología que se utiliza se basa en un diseño centrado en los alumnos con diversos tipos de discapacidad y en los docentes como usuarios potenciales del repositorio y de los programas pedagógicos propuestos.

Palabras clave: necesidades educativas especiales, herramientas tecnológicas, programa pedagógico, integración educativa.

\footnotetext{
1 S. J. Romero Martínez, profesora titular de la Universidad a Distancia de Madrid (UDIMA).

2 I. González Calzada, egresada del Máster en Educación y Nuevas Tecnologías de la Universidad a Distancia de Madrid (UDIMA).

${ }^{3}$ A. García Sandoval, egresada del Máster en Educación y Nuevas Tecnologías de la Universidad a Distancia de Madrid (UDIMA).

${ }^{4}$ A. Lozano Domínguez, egresada del Máster en Educación y Nuevas Tecnologías de la Universidad a Distancia de Madrid (UDIMA).
} 


\section{Technological tools}

\section{for inclusive}

\section{education}

\section{Abstract:}

Among the possibilities that the incorporation of information and communication technologies (ICT) offers to education is attention to diversity, since through these tools, access and quality education can be facilitated to students with different special educational needs. There are different types of disabilities (motor disabilities, sensory disabilities and intellectual disabilities) with many different types of manifestations. Students with these types of disabilities face the difficulty of having equal access to education. Despite the fact that progress has been made in terms of integration, this efforts should be increased to achieve it completely.

For this reason, the goal of this work is to make a repository of technological tools and teaching activities for each type of disability and present a pedagogical program for the application of these in specific cases that allow us to use new technologies at the service of integration of students with disabilities. To achieve this goal, an empirical qualitative-descriptive study has been carried out in which a repository of the main existing applications for work with students of various disabilities is presented, analyzing their advantages and disadvantages. The methodology used is based on a design focused on students with different types of disabilities and on teachers as potential users of the repository and the proposed pedagogical programs.

Keywords: special educational needs, technological tools, pedagogical program, educational integration.

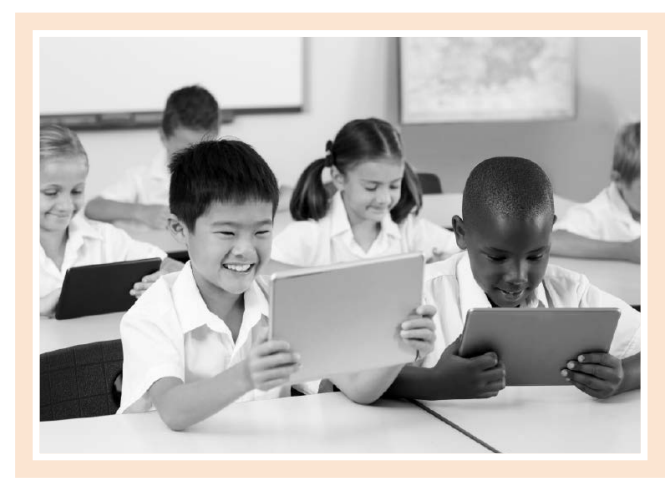

Todos tenemos la esperanza de que el mundo pueda ser un lugar mejor donde vivir y la tecnología puede colaborar para que ello suceda

Tim Berners-Lee

\section{INTRODUCCIÓN}

La educación es un proceso complejo con grandes dificultades, retos y expectativas. Una de las principales metas de cualquier sistema educativo, desde la educación infantil hasta el nivel universitario, es garantizar la igualdad entre todos los estudiantes. La pregunta que enmarca este reto es si resulta posible atender a la diversidad que existe entre los alumnos, sobre todo cuando esta se asocia con el término «discapacidad», y lograr una formación de excelencia, teniendo en cuenta que el proceso de escolarización debe asegurar que cada una de las personas consiga el máximo desarrollo posible dentro de sus capacidades, intereses y motivaciones, que son únicas e individuales.

En este contexto se hace referencia a la llamada «diversidad en el ámbito educativo», que se refiere a las características heterogéneas que tiene cada estudiante y que generan necesidades diferenciales que también requieren diversas medidas, diferentes metodologías y distinto apoyo pedagógico. Dichas necesidades diferenciales reciben el nombre de «necesidades educativas especiales» 0 «específicas» (NEE) (Blanco, 1990). La Ley orgánica 2/2006, de 3 de mayo, de educación (LOE) define a los alumnos con NEE como aquellos que presentan 
necesidades educativas especiales, es decir, alumnos con dificultades específicas de aprendizaje que, por sus altas capacidades intelectuales, por haberse incorporado tarde al sistema educativo o por condiciones personales o de historia escolar, requieren una atención educativa diferente a la ordinaria para que puedan alcanzar el máximo desarrollo posible de sus capacidades personales y, en todo caso, los objetivos establecidos con carácter general para todo el alumnado (art. 71.2).

La llamada «diversidad en el ámbito educativo» se refiere a las características heterogéneas que tiene cada estudiante y que generan necesidades diferenciales que también requieren diversas medidas, diferentes metodologías y distinto apoyo pedagógico.

El término «NEE» fue acuñado a finales de los años setenta en el Informe Warnock (Warnock, 1981). Este informe, realizado por Mary Warnock en el Reino Unido, hizo énfasis en el apoyo que requieren los alumnos con NEE desde un punto de vista inclusivo, eliminando las barreras que existían hasta ese momento entre los estudiantes que requerían una «educación especial» y los que requerían una «educación normal». Antes del citado informe solo los alumnos con discapacidad tenían apoyos y recursos especiales, quedando excluidos aquellos alumnos que presentaban otro tipo de dificultades de aprendizaje.

Otro de los hitos fundamentales para el cambio de la concepción en la educación especial fue la Conferencia Mundial sobre NEE celebrada en Salamanca en 1994 (United Nations Educational, Scientific and Cultural Organization [UNESCO], 1994). En dicha conferencia, 92 Gobiernos y 25 organizaciones internacionales se comprometieron a insertar en un sistema educativo común a los alumnos con discapacidad. Esta conferencia constituyó otro gran avance para potenciar un cambio en el que se pasó de la escolarización de las personas con NEE en centros específicos a su integración en centros ordinarios. La Declaración de Salamanca hacía énfasis en los beneficios de la integración para evitar la segregación y la marginación de las personas con discapacidad y, a su vez, facilitaba un entorno de aceptación y respeto a la diversidad para los alumnos sin discapacidad. Como hemos visto, a partir del Informe Warnock y de la Declaración de Salamanca se abrió un nuevo punto de vista respecto a la comprensión de la discapacidad, dejando de lado la perspectiva individualista, donde las dificultades están en el

\section{La llamada udiversidad en el ámbito educativo» se refiere a las características heterogéneas que tiene cada estudiante y que generan necesidades diferenciales que también requieren diversas medidas, diferentes metodologías y distinto apoyo pedagógico}

alumno particular, y pasando a una perspectiva contextual, donde las NEE interactúan con el contexto, son cambiantes, complejas y relativas.

Este cambio implica que la actividad educativa se plantea como la búsqueda de las ayudas necesarias para que todos los alumnos, en especial los que tienen NEE, puedan lograr los objetivos que se marcan como básicos en cada etapa. Simultáneamente se comenzó a ampliar y normalizar el concepto, partiendo de que uno de cada cinco estudiantes puede requerir algún tipo de apoyo puntual o permanentemente y teniendo en cuenta también que las diferencias que pueden presentar los alumnos con NEE son muy diversas (Aguilar, 1991). La respuesta educativa a estas situaciones se refleja en currículos cada vez más abiertos y flexibles que establecen unos aprendizajes mínimos a partir de los cuales la Administración construye sus propuestas didácticas adaptadas a las características del alumnado y alejadas de la rigidez en el proceso pedagógico.

A pesar de estos esfuerzos y de que han transcurrido 40 años desde que la escuela ordinaria se ha enfrentado al reto de integrar al alumnado con discapacidad dentro de sus aulas, el cambio no ha sido suficiente. En algunas ocasiones la integración se basa en la integración física (asistir a clases en el mismo recinto), sin producirse una integración real, contextual, social y educativa dentro del proceso de enseñanza y aprendizaje. Podemos afirmar que aún no se ha producido una integración social ni intelectual real. La promoción de aulas inclusivas, integradoras, que dan cabida a todos, atendiendo a las necesidades individuales de cada uno, sigue siendo una asignatura pendiente en educación. 
Tal y como indica Ainscow (1995), se hace necesario pasar de una perspectiva individual a una perspectiva curricular, lo que implicará la adaptación de los contenidos, de los objetivos y de la metodología, teniendo en cuenta las diferentes necesidades del grupo. Es decir, el objetivo de la escuela inclusiva es de mayor magnitud, pues «se trata de transformar la cultura, la organización y las prácticas educativas de las escuelas comunes para atender a la diversidad de necesidades educativas del alumnado, de todo el alumnado» (Cabero y Córdoba, 2009, pág. 62).

La inclusión implica que todos los alumnos tienen derecho a obtener las ayudas necesarias, de acuerdo a sus necesidades, sin distinciones en función de su sexo, raza, procedencia o tipo de discapacidad; en otras palabras, siguiendo un principio de igualdad. Aunque las investigaciones realizadas en el área confluyen en los muchos beneficios que la inclusión educativa aporta en el alumnado y en la sociedad, en la práctica se siguen llevando a cabo modelos de escuela tradicional cuyas prácticas no promueven la inclusión (García Gómez y García Pastor, 2007). Algunos ejemplos de actuaciones que siguen centrándose en dicho modelo tradicional son los apoyos fuera del aula, currículos individualizados y tareas con objetivos diferentes. El cambio en la escuela está al alcance de los docentes. En sus manos queda la planificación, la formación y la innovación en el trabajo con el alumnado que presenta NEE. La Universidad Internacional de Valencia (s. f.) recomienda seguir las siguientes prácticas para favorecer la inclusión educativa:

- Proporcionar diversidad en los métodos de enseñanza y personalizar las diferentes experiencias de aprendizaje.

- Fomentar la participación de los padres en las actividades escolares y en el progreso de sus hijos.

- Diálogo y aprobación de todos los miembros de la comunidad educativa: profesores, padres y alumnado.

- El centro debe realizar actividades que conlleven el trabajo colaborativo con diferentes instituciones, empresas y asociaciones del entorno.

- Crear lazos de convivencia y tolerancia entre toda la comunidad escolar, promoviendo la confianza en los demás y el respeto a la diversidad.

- Prevenir la exclusión, realizando actividades que fomenten la aceptación de la diversidad y la interculturalidad.
- Contar con los recursos necesarios para satisfacer las necesidades que puedan presentar todos los alumnos (incluyendo a aquellos estudiantes que requieran de recursos específicos, tales como profesores de apoyo, materiales informáticos o didácticos, etc.), promoviendo en todo momento el derecho a la inclusión y el principio de equidad.

Como se ha visto hasta el momento, para conseguir una educación de calidad, que dé respuesta a la diversidad de todo el alumnado, lo que ha venido a denominarse "pedagogía de la complejidad», hay que plantearse un esfuerzo común entre todos los profesionales de la educación (Gimeno, 2000). La evolución hacia dicha educación, aunque lenta, parece en marcha en las etapas obligatorias, donde se ha evolucionado de modelos basados en la exclusión, pasando por modelos segregadores, a un modelo que defiende la integración, aunque desde una perspectiva asimilacionista (Parrilla, 2002). Las investigaciones que abordan este tema indican que las posibilidades de integración e inclusión del alumnado con necesidades educativas especiales son menores cuando se va progresando en el nivel educativo; de esta forma, la inclusión suele ser más sencilla en etapas como educación infantil, es fácil en educación primaria, si se cuenta con los recursos adecuados, pero en educación secundaria y en la etapa universitaria cada vez va siendo más difícil (Echeita y Navarro, 2014).

La inclusión supone ir un paso más allá al plantear el concepto de «barreras para el aprendizaje y la educación». Este concepto implica que las barreras no están en el alumnado, sino que el propio sistema educativo y la sociedad son los que condicionan las oportunidades que tienen los estudiantes para aprender y para participar en sus centros (Echeita y Navarro, 2014). El peligro de estas barreras, señalan los autores, es que en muchos casos suponen una exclusión encubierta; por ejemplo, cuando pretendemos que todos los alumnos aprendan lo mismo, al mismo tiempo y de la misma forma. Para Ainscow (1995), hablar de inclusión en cualquier etapa educativa, por tanto, supone no solo que todos puedan acceder a los mismos estudios y a los mismos centros (presencia), sino que todos puedan lograr el máximo desarrollo de sus capacidades (rendimiento) y que todos se sientan una parte importante de sus centros (participación). 
Es por este motivo por el que surge la necesidad de una transformación del sistema educativo mediante un compromiso social con la educación inclusiva. A través de dicho compromiso se trata de «transformar la cultura de la organización y las prácticas educativas para atender la diversidad de necesidades educativas de todo el alumnado» (Cabero y Córdoba, 2009, pág. 62). Tal y como indica Ainscow (1995), se hace necesario pasar de una perspectiva individual a una perspectiva colectiva, organizacional, lo que implicará la adaptación de los contenidos, de los objetivos y de la metodología, teniendo en cuenta las diferentes necesidades del alumnado. La educación inclusiva representa una gran esperanza para conseguir una sociedad más justa, equitativa y solidaria (Gallego y Rodríguez, 2012). Las TIC son una fuente de recursos en continuo avance que nos permiten atender a la diversidad, afrontando las limitaciones y barreras que en ocasiones puedan generarse. La globalización (y por ende, la atención a la diversidad) gira en torno a las TIC como «elemento básico para su desarrollo y potenciación» (Cabero y Córdoba, 2009, pág. 69). El uso de las TIC nos ofrece múltiples ventajas en nuestras aulas inclusivas, destacando las siguientes:

- Ayudan a superar las limitaciones derivadas de diferentes discapacidades sensoriales, motrices 0 intelectuales.

- Generan una atención más personalizada del alumnado.

- Favorecen la comunicación en sus diferentes modalidades (sincrónica o asincrónica, feedback, etc.).

- Promueven la autonomía de los alumnos.

- Ahorran tiempo.

- Atienden a la diversidad (inteligencias múltiples, estilos de aprendizaje, información multisensorial, etc.).

- Facilitan el acceso a múltiples recursos de información, proporcionando momentos de ocio y de aprendizaje.

Concretamente, nuestro trabajo versará sobre las habilidades, las destrezas, las herramientas y los materiales que promueven la educación inclusiva, definiéndola como aquella encaminada a buscar la equidad e igualdad de derechos entre todas las personas y así prevenir la brecha digital que pueda derivar de ciertas situaciones. Por este motivo, las preguntas que orientan la presente investigación son:
- ¿Cuáles son las herramientas TIC que nos permiten una educación más inclusiva e integral?

- ¿Cuál es el diseño pedagógico más apropiado para la aplicación de dichas herramientas tecnológicas?

Para dar respuesta a estas preguntas nos hemos planteado los siguientes objetivos:

- Objetivo general. Describir y analizar las diversas aplicaciones que se han propuesto mediante las TIC para la educación de los estudiantes con discapacidad.

\section{- Objetivos específicos:}

- Describir las diversas aplicaciones que se están utilizando para la enseñanza de personas con discapacidad.

- Diseñar un esquema de trabajo estructurado sobre la forma en que se pueden usar las diversas aplicaciones en el contexto de enseñanza-aprendizaje de cada una de las discapacidades concretas.

- Promover la interactividad entre los alumnos y entre los alumnos y los docentes a través de tareas, programas de gestión, videojuegos, materiales formativos, multimedia, sistemas expertos específicos, etc.

- Facilitar el acceso y la difusión de la propuesta pedagógica para que pueda ser utilizada en centros educativos.

A continuación, y antes de presentar el repositorio de actividades, se incluye el marco teórico y conceptual en el que se enmarca nuestro trabajo.

\section{MARCO TEÓRICO}

\subsection{Discapacidad y TIC}

Actualmente nos encontramos inmersos en la sociedad de la información y el conocimiento, y, por ello, las TIC nos brindan múltiples posibilidades para enriquecer nuestros procesos de enseñanza-aprendizaje y llegar a distintos colectivos. De forma generalizada, las TIC potencian habilidades como el trabajo cooperativo, el desarrollo de prácticas innovadoras, fomentan las competencias digitales, la alfabetización tecnológica, nuevas formas de socialización, etc. Es decir, encontramos en ellas un gran potencial, ya que ofrecen una 


\section{Las posibilidades y las ventajas que ofrecen las TIC para atender a la diversidad son múltiples: ayudan a superar las limitaciones que se derivan de las discapacidades cognitivas, sensoriales y motrices del alumnado; favorecen la autonomía de los estudiantes, pudiéndose adaptar a las necesidades y demandas de cada alumno de forma personalizada; etc.}

gran pluralidad de recursos y contenidos para reforzar distintos procesos de aprendizaje. Las TIC incorporan, cada vez con más frecuencia, elementos, aplicaciones e innovaciones que favorecen la inclusión del alumnado con NEE. Asimismo, existen recursos tecnológicos, basados en el uso de las TIC, que han sido diseñados específicamente para posibilitar la accesibilidad de las personas con discapacidad.

Como señalan Cabero y Córdoba (2009), el papel de las TIC en relación a las personas con discapacidad es fundamental, en el sentido de que les va a posibilitar la comunicación con otros individuos y con su entorno, y les puede facilitar su aprendizaje o su integración en el mundo laboral. El acceso de las personas con discapacidad a la denominada "sociedad del conocimiento» es un eslabón clave para su integración, desarrollo y participación. Muchas de las personas con discapacidad no podrían acceder a la información o no podrían comunicarse con otros individuos si no fuera gracias a determinadas tecnologías.

Las posibilidades y las ventajas que ofrecen las TIC para atender a la diversidad son múltiples: ayudan a superar las limitaciones que se derivan de las discapacidades cognitivas, sensoriales y motrices del alumnado; favorecen la autonomía de los estudiantes, pudiéndose adaptar a las necesidades y demandas de cada alumno de forma personalizada; ofrecen un feedback inmediato; respaldan un modelo de comunicación y de formación multisensorial; propician una formación individualizada, en la que el alumnado puede avanzar a su propio ritmo; favorecen el desarrollo de la autonomía y la independencia de las personas; y potencian la disminución del sentido de fracaso académico y personal, pues los estudiantes suelen sentirse más motivados (Negre, 2003; Cabero, Córdoba y Fernández, 2007; Hervás y Toledo, 2007; Ortega-Tudela y Gómez-Ariza, 2007). No obstante, para hacer un uso adecuado de las TIC, no podemos olvidar que «su utilización va a depender del tipo de discapacidad al que nos estemos refiriendo y del grado de la misma, que su utilización tenemos que percibirla tanto desde el punto de vista del hardware (componente físico de los ordenadores: teclados, impresoras, etc.) como del software (componente lógico: programas informáticos, navegadores, etc.) y que en su investigación y análisis entrarán en juego diferentes profesionales, tales como pedagogos, ingenieros, psicólogos, diseñadores y profesores» (Cabero, Córdoba y Fernández, 2007, págs. 16-17).

A rasgos generales, existen un gran número de tecnologías diferentes dentro de un conjunto de ayuda según las áreas de ejecución (Cook y Polgar, 2000):

- Sistemas alternativos y aumentativos de acceso a la información del entorno.

- Ayuda para personas con discapacidad visual y/o auditiva (sistema en braille, carteles icónicos, audífonos, etc.).

- Tecnologías de acceso al ordenador (Adaptative Technology): todos los sistemas (hardware y software) que permiten a personas con discapacidad física o sensorial utilizar los sistemas informáticos convencionales.

- Sistemas alternativos y aumentativos de comunicación: para las personas que no pueden utilizar el código verbal-oral-lingüístico de comunicación.

- Tecnologías para la movilidad personal: todos los sistemas para facilitar la movilidad, como sillas de ruedas (manuales y/o autopropulsadas), adaptaciones para vehículos de motor, etc.

- Tecnologías para la manipulación y el control del entorno: sistemas electromecánicos para personas con discapacidades físicas o sensoriales (incluyen robots, dispositivos de apoyo para la manipulación, sistemas electrónicos, etc.).

Luna (2013) clasifica los recursos TIC diseñados de manera concreta para personas con discapacidad en las siguientes categorías: 
- Por la finalidad de uso: educativo, simulador de vida independiente, diversión, accesibilidad, movilidad y como medio de comunicación.

- Por el costo de adquisición: alto costo, costo medio, bajo costo y gratuitos.

- Por el medio de acceso: compra, creación personalizada, descarga gratuita y en línea.

- Por el tipo de materiales que ofrecen: recursos interactivos, recursos para impresión y recursos para diseño.

- Por el tipo de tecnología: software, hardware, switch, simuladores, realidad virtual y realidad aumentada.

- Por el tipo de medios que utilizan: vídeos, audio, texto, imagen y animaciones.

- Por el tipo de discapacidad: motora, visual, auditiva, intelectual, trastorno por déficit de atención con o sin hiperactividad (TDAH), autismo y otros trastornos en el desarrollo.

Aunque, como ya hemos comentado, cada vez es más habitual encontrar recursos específicos, si nos centramos en el terreno educativo, esto no siempre es posible. En las aulas hay alumnos muy diversos, por lo que es también importante crear materiales que sean accesibles para todos, es decir, materiales multisensoriales y materiales multimedia.

Como ya se ha dicho anteriormente, la educación debe ser para todos, pero esto no significa única y exclusivamente que todos los estudiantes estén en el sistema educativo y en la misma aula, sino que todos aprendan y lleguen al máximo de su desarrollo en el nivel en el que se encuentren. Debemos ser conscientes de que todos somos diferentes y de que hay que respetar esas diferencias; por ello, es necesario plantear modelos, metodologías y respuestas didácticas que permitan aprender a aprender y lograr los objetivos planteados en un contexto inclusivo con el apoyo de las TIC.

\subsection{Diseño de herramientas y materiales adaptados}

La convergencia de las TIC en los procesos de enseñanza-aprendizaje hace indispensable su adaptación en los diferentes contextos y necesidades educativas frente a los que nos encontremos.
Es por ello que las tecnologías son concebidas como mediadoras en los procesos de enseñanza y aprendizaje y suponen que las capacidades no son algo fijo, sino que también se definen en la interacción entre las capacidades del estudiante y las herramientas que emplea en estos procesos.

Tal como indica Álvarez (2011), el diseño universal o «diseño para todos» se concibe como la actividad que posibilita procesos, bienes, productos, servicios, objetos, instrumentos, dispositivos y herramientas empleados por todas las personas, favoreciendo la igualdad de oportunidades y su inclusión en la sociedad. Concretamente, a la hora de diseñar materiales y herramientas TIC, se contemplan una serie de etapas generales: selección de los elementos del currículo, búsqueda de recursos digitales existentes, definición de los principios de diseño estructural y funcional, elección de la herramienta de edición, diseño del guion multimedia, edición y montaje del recurso, elaboración de la guía didáctica y del material complementario, pilotaje de la versión beta y publicación de la versión definitiva.

No obstante, para ofrecer prácticas educativas de calidad y favorecer la inclusión de todos nuestros alumnos por medio de materiales y herramientas TIC adaptados, con el fin de que puedan desarrollar las dinámicas del aula, nos atenemos a parámetros específicos que promueven normativas del siguiente tipo:

- I Plan Nacional de Accesibilidad 2004-2012. Por un Nuevo Paradigma, el «Diseño para Todos», hacia la Plena Igualdad de Oportunidades. Parte de dos principios básicos y fundamentales (Instituto de Mayores y Servicios Sociales [IMSERSO], 2003):

- El respeto a la diversidad humana y la equiparación de derechos de todas las personas como bases fundamentales de nuestra sociedad.

- Las barreras en el entorno, concebidas como obstáculos más graves a la participación social que las limitaciones funcionales de las personas.

- Reglamento sobre las condiciones básicas para el acceso de las personas con discapacidad a las tecnologías, productos y servicios relacionados con la sociedad de la información y medios de comunicación social. Los equipos informáticos y los programas de ordenador, independientemente de que sean libres o estén sometido a derechos 
de patente 0 al pago de derechos utilizados por las Administraciones públicas, cuyo destino sea el uso por el público en general, deberán ser accesibles a las personas mayores y personas con discapacidad (BOE, 2007).

De acuerdo con estos precedentes, podemos establecer una serie de condicionantes que consideramos relevantes para dotar al aula con herramientas y actividades tecnológicas de calidad y adaptadas a las necesidades de los alumnos con discapacidad:

- Perceptibilidad para reconocer los elementos y las funciones básicas de los materiales y recursos tecnológicos (letra, brillo, voz, símbolos, lenguaje adaptado, audición [discriminando sonido y fondo], etc.).

- Contenidos con estructura flexible para adaptarla a cambios oportunos.

- Operabilidad (ofrecer facilidades para navegar, localizar contenido y determinar dónde se encuentran, selección mediante teclado u otros medios, etc.).

- Comprensibilidad (facilitar la organización y la cohesión de sus elementos, así como su lectura sencilla, evitando contenidos robustos o excesivos).

Por medio de estas pautas generales, estaremos favoreciendo la inclusión, ya que proporcionaremos múltiples medios de representación o diferentes maneras de abordar el contenido según los distintos ti- pos de discapacidades. Además, estaremos ofreciendo distintos medios de expresión oral y escrita, adecuados para abordar los contenidos, y favoreceremos la motivación para alcanzar los objetivos del currículo, implicando a todos los alumnos, independientemente de su condición.

\subsection{Breve definición de los tipos de dis- capacidad que se abordan en este tra- bajo}

En el presente estudio se parte de una definición amplia y contextual de la discapacidad, teniendo en cuenta que algunos tipos de discapacidad tienen su origen en experiencias vividas, en historias personales o educativas que no han permitido a las personas desarrollarse adecuadamente, y que otros tipos pueden ser la consecuencia de vivir en ambientes marginales 0 en determinadas culturas. Según el Instituto Nacional de Tecnologías Educativas y de Formación del Profesorado (INTEF), de forma general, podemos clasificar las necesidades de estos alumnos en los grupos que se pueden observar en la tabla 1.

En el presente trabajo se abordan herramientas TIC relacionadas con la discapacidad motriz, con el autismo y con el TDAH. A continuación se presenta una breve definición de cada una de ellas.

Tabla 1. Necesidades especiales de los alumnos

Condiciones personales o de historia escolar

\begin{tabular}{|c|c|}
\hline \multicolumn{2}{|r|}{ Condiciones personales o de historia escolar } \\
\hline $\begin{array}{l}\text { Trastorno grave de desarrollo del lenguaje } \\
\text { y de la comunicación }\end{array}$ & - Asociados a causas orgánicas, cognitivas, psicolingüísticas o sociofamiliares. \\
\hline Trastorno del aprendizaje & - Dislexia, discalculia, etc. \\
\hline Otras necesidades específicas & $\begin{array}{l}\text { - Déficit de atención. } \\
\text { - Minorías étnicas. } \\
\text { - Situación sociofamiliar desfavorecida. } \\
\text { - Situación de riesgo sociofamiliar y/o protección del menor. } \\
\text { - Alumnado itinerante o temporal. }\end{array}$ \\
\hline
\end{tabular}


Tabla 1. Necesidades especiales de los alumnos (cont.)

\begin{tabular}{|c|c|}
\hline \multicolumn{2}{|r|}{ Necesidades educativas especiales } \\
\hline Discapacidad psíquica & $\begin{array}{l}\text { - Psíquico medio. } \\
\text { - Psíquico ligero. }\end{array}$ \\
\hline Discapacidad auditiva & $\begin{array}{l}\text { - Sordera total (cofosis). } \\
\text { - Sordera parcial (hipoacusia). }\end{array}$ \\
\hline Discapacidad visual & $\begin{array}{l}\text { - Ceguera legal (agudeza visual igual o inferior a } 1 \text { grado o } 1 / 10 \text { de la escala de Wecker). } \\
\text { - Discapacidad visual (campo visual disminuido a } 10 \text { grados o menos). }\end{array}$ \\
\hline Discapacidad motriz & $\begin{array}{l}\text { - Parálisis cerebral. } \\
\text { - Espina bífida. } \\
\text { - Distrofia muscular. }\end{array}$ \\
\hline Trastorno generalizado del desarrollo & $\begin{array}{l}\text { - Autismo. } \\
\text { - Sindrome de Asperger. } \\
\text { - Síndrome de Rett. } \\
\text { - Trastorno desintegrativo infantil. }\end{array}$ \\
\hline $\begin{array}{l}\text { Trastornos graves de conducta, persona- } \\
\text { lidad o comportamiento }\end{array}$ & $\begin{array}{l}\text { - Trastorno grave de la personalidad y/o de la conducta. } \\
\text { - TDAH. }\end{array}$ \\
\hline Plurideficientes & - Alteraciones neurológicas y físicas. \\
\hline
\end{tabular}

Fuente: adaptación realizada por las autoras partiendo de la clasificación del INTEF (2015).

\subsubsection{Discapacidad motriz}

Al tratar las minusvalías y, más concretamente, las discapacidades motrices, debemos atenernos no solo a los elementos claramente perceptibles, sino también a los condicionantes de tipo social, relacional e institucional, los cuales debemos subsanar paulatinamente. Es precisamente por medio de este trabajo por el que pretendemos ofrecer alternativas, a través del uso de las TIC, para que el alumnado con discapacidad motriz normalice su vida escolar y adquiera habilidades funcionales necesarias.

Cuando hablamos de alumnos que presentan necesidades motrices nos estamos refiriendo a sujetos que mani- fiestan problemas en la ejecución de sus movimientos, independientemente de la causa desencadenante (motriz generalizado, psíquico o sensorial). Además, debemos puntualizar que todos estos trastornos motrices se ven ampliados si observamos la afección directa sobre caracteres físicos, logopédicos, intelectuales, relacionales y educativos. Generalmente, entre las causas que originan trastornos motrices se encuentran lesiones 0 enfermedad del sistema nervioso, factores traumáticos, metabólicos, infecciones, genéticos, etc., que pueden desarrollarse en diferentes momentos evolutivos, y estaremos ante problemas motrices más graves cuando la afección sea intrauterina. Todo ello nos permite distinguir deficiencias motrices según sus causas y la función del nivel y alcance de la lesión o déficits: encefalopatías 
connatales, encefalopatías posnatales, infecciones, déficits malformativos y parálisis obstétricas.

En consecuencia, para determinar una tipología, nos vamos a centrar en aquellos que tienen más influencia en el ámbito educativo y de la educación especial. Siguiendo las clasificaciones ofrecidas por Aguado y Alcedo (1991), distinguimos:

- Trastornos con afectación cerebral. Se consideran como una de las causas más frecuentes de minusvalía física y su diagnóstico implica la existencia de una lesión cerebral no progresiva cuya causa puede ser de origen prenatal, perinatal o posnatal. Se caracterizan por un desorden del tono, de la postura y del movimiento, y se manifiestan en la maduración neurológica, además de en los efectos secundarios asociados y derivados de dicha lesión (Alexander y Bauer, 1988). Es frecuente asociar la parálisis cerebral a trastornos como retraso mental, dificultades de aprendizaje, trastornos del lenguaje, epilepsia y problemas sensoriales. Por ello, resulta difícil encuadrar un tipo concreto de parálisis cerebral y, de este modo, recurrimos a su sintomatología: alteraciones del tono muscular y del movimiento (asociados también a trastornos sensoriales visuales y auditivos), problemas perceptivos y deficiencia mental (viéndose principalmente afectado el desarrollo motor). Identificamos distintos tipos de parálisis cerebral según sus características neuromusculares.

La clasificación más aceptada es la ofrecida por Hartlage (1983). Según los síntomas, se distingue entre:

- Espasticidad. Incremento del tono muscular.

- Atetosis. Dificultad en el control y en la coordinación.

- Ataxia. Dificultad para medir la fuerza, la distancia y la dirección de los movimientos.

- Rigidez. Hipertonía que impide el movimiento.

- Temblores. Movimientos oscilantes y rítmicos.

Según los miembros afectados, se clasifican en:

- Monoplejia. Afecta a una sola extremidad.

- Hemiplejia. Afecta al brazo y a la pierna del mismo lado.

- Displejia. Afecta a ambas extremidades inferiores, y a los brazos, parcialmente.

- Triplejia. Un brazo se encuentra menos afectado que las otras tres extremidades.

- Tetraplejia. Afecta a las cuatro extremidades.
- Trastornos sin afectación cerebral. Definimos este tipo de enfermedades como aquellas que no son inducidas por lesión cerebral y, por ello, presentan menos dificultades a nivel social, personal y educativo. Distinguimos diversos tipos:

- Poliomelitis. Se trata de una enfermedad epidémica y, gracias a las vacunas, su aparición es prácticamente nula. Produce un ataque inflamatorio de las astas anteriores de la médula que origina degeneración de músculos completos, atrofias musculares, y destruye neuronas motrices.

- Espina bífida. Déficit o desarrollo insuficiente del cierre del canal óseo de la columna vertebral. La persona afectada no percibe ciertas sensaciones cutáneas (dolor, presión y temperatura) ni sensaciones para controlar la micción. En caso de que se solape con hidrocefalia, se debe recurrir a la intervención quirúrgica. No obstante, en casos más ligeros puede desarrollarse entrenamiento conductual y programas educativos dirigidos hacia este trastorno.

- Miopatías. Son trastornos físicos asociados a distrofia muscular, caracterizados por una progresiva degradación de masa muscular sin afectación del sistema nervioso. Su origen es genético, aunque los primeros síntomas pueden presentarse de forma progresiva durante los primeros años de vida.

\subsubsection{Autismo}

Los trastornos del espectro autista (TEA) son alteraciones del desarrollo que se caracterizan por la presencia de dificultades específicas en las áreas social, comunicativa y cognitiva. El Manual diagnóstico y estadístico de los trastornos mentales (DMS-IV), de la Asociación Americana de Psiquiatría (American Psychiatric Association [APA]), emplea el término bajo la denominación de "trastornos generalizados de desarrollo» (TGD) y, dentro de ellos, incluye el autismo, el trastorno desintegrativo infantil, el síndrome de Asperger, el síndrome de Rett y el trastorno generalizado del desarrollo no especificado (autismo atípico).

\section{A) Características del autismo}

De acuerdo con el DSM-IV, el autismo se caracteriza por tres síntomas de base (tríada), que son:

- Alteración en la reciprocidad social. Implica el atraso en el desarrollo de habilidades sociales, pu- 
diendo presentar dificultades para mantener relaciones; comportamientos no adecuados en diferentes contextos sociales; dificultades para compartir juegos; ausencia de interés por las personas; y dificultades en la reciprocidad social y emocional que pueden tener varias manifestaciones, como un acercamiento social anormal, una incapacidad para mantener una conversación, la reducción de intereses, emociones y afectos compartidos o la ausencia total de iniciativa en la interacción social.

- Déficits en la comunicación y el lenguaje. Implica la falta de uso del lenguaje como comunicación funcional. Incluso en los casos más graves puede producirse mutismo. Algunos niños inician el desarrollo del lenguaje en el primer año de vida, pero pueden sufrir una regresión posterior y perderlo. Otros ya sufren retrasos generalizados en todos los aspectos del lenguaje y la comunicación (no compensan con gestos o mímica). Cuando el lenguaje está presente, existe una alteración importante de la capacidad para mantener una conversación: ecolalia, confusión de pronombres personales (suelen referirse a ellos mismos en segunda o en tercera persona), repetición de frases alrededor de un tema particular y anormalidades en la prosodia. Tienden a utilizar un lenguaje estereotipado y repetitivo.

- Patrones de comportamiento, actividades e intereses restringidos y repetitivos. Comportamiento estereotipado o repetitivo (por ejemplo, manipulación repetitiva de objetos, o movimientos corporales, como sacudir o girar las manos o los dedos). Excesiva fijación con las rutinas y resistencia al cambio (por ejemplo, insistencia en tomar los mismos alimentos o jugar siempre con el mismo objeto). Intereses altamente restrictivos y fijos de intensidad desmesurada (por ejemplo, fuerte preocupación por objetos inusuales).

\section{B) Clasificaciones del autismo}

Tradicionalmente, para clasificar el autismo se ha utilizado el Manual diagnóstico y estadístico de los trastornos mentales (DMS), de la APA, en sus diversas versiones. El autismo aparece clasificado por primera vez en el DSM-II (APA, 1968) como una reacción psicótica de la infancia; posteriormente, en el DSM-III (APA, 1980), recibe el nombre de «autismo infantil», agrupado bajo una nueva categoría denominada «TGD», término que denotaba una afección global del desarrollo del niño. El DSM-III-R (APA, 1987) cambió el nombre de "autismo infantil» a «trastorno autista», por lo que los criterios de diagnóstico se ampliaron y las formas no autistas se agruparon en la categoría denominada «problemas generalizados del desarrollo no especificados» (TGD-NE) (Waterhouse, Wing, Spitzer y Siegel, 1992). En el DSM-IV (APA, 2000), el autismo permaneció clasificado como un TGD con criterios claros, aunque menos restrictivos, que motivaron un aumento en la prevalencia de los casos de autismo. En la actualidad, la nueva edición del manual DSM-V está modificando la clasificación y los criterios diagnósticos de estos trastornos.

\subsection{3. $T D A H$}

Según la Clasificación Internacional de Enfermedades y el Manual diagnóstico y estadístico de los trastornos mentales (DSM-IV-TR), el TDAH es un trastorno neurobiológico de comportamiento que aparece en la infancia, la niñez o la adolescencia por factores genéticos y/o ambientales y que afecta aproximadamente a un $7 \%$ de los niños, siendo el trastorno más común en la edad escolar, sobre todo en el sexo masculino.

Investigaciones recientes afirman que se produce por un desequilibrio en los neurotransmisores, que se encargan del funcionamiento de la corteza prefrontal y causan alteraciones en las funciones ejecutivas, dificultando la organización, la planificación, la priorización, la precipitación en la respuesta o el déficit de atención. El TDAH suele mostrar un patrón repetitivo de desatención y/o hiperactividad-impulsividad, aunque no todos los niños con el trastorno manifiestan los mismos síntomas ni la misma intensidad. Sus síntomas son:

- Impulsividad. El niño no controla sus conductas, emociones y pensamientos. Implica una falta de control a nivel motriz y emocional que le lleva a no pensar en las consecuencias de sus acciones. Las manifestaciones más comunes del niño con impulsividad en el entorno escolar son:

- No analizan ni reflexionan las situaciones.

- No miden las consecuencias de sus acciones.

- Actúan impulsivamente, haciendo lo primero que se les ocurre. 
- Responden sin pensar.

- No tienen en cuenta las advertencias.

- No tienen sentido del peligro.

- No terminan sus tareas.

- Les resulta muy difícil seguir instrucciones, ya que no son capaces de inhibir la conducta.

- No controlan demasiado bien la expresión de los sentimientos.

- Los castigos y las recompensas a largo plazo no les producen efecto.

- Hiperactividad. Se trata de una actividad excesiva o inapropiada en relación a la edad del niño. Implica un exceso de movimiento en el niño, que parece no poder estar nunca quieto. Las manifestaciones más comunes en el entorno escolar son:

- Se levantan del asiento continuamente.

- Se sientan de manera inadecuada.

- Corretean y/o deambulan por la clase.

- Muerden y/o chupan cualquier cosa, como material escolar, sin darse cuenta.

- Interrumpen constantemente.

- Son poco cuidadosos y muy ruidosos.

- Pueden ser molestos e incontrolables.

- Les llaman la atención las actividades con más «peligro», lo que ocasiona que tengan muchos accidentes.

- Inatención. Consiste en una dificultad para concentrarse, prestar atención durante un tiempo (atención sostenida) y seleccionar información relevante (atención selectiva). Responden mejor a tareas conocidas que se realicen de manera automática. Las manifestaciones más comunes del niño inatento son:

- Realización de tareas de manera variable e inconsistente.

- Suelen ser desorganizados y distraídos.

- Tardan en comenzar la realización de las tareas.

- Tienen dificultades para establecer prioridades y planificar actividades.

- Tienen problemas para seguir una conversación.

- Se cansan de las tareas que requieren más tiempo.

- Sus trabajos suelen estar deteriorados.

- Su atención solo se manifiesta en las cosas que les gustan.
Según los síntomas predominantes, se presentan tres subtipos de TDAH:

- Subtipo con predominio hiperactivo-impulsivo.

- Subtipo con predominio de inatención.

- Subtipo combinado.

Por su parte, muchos de ellos llevan asociados otros trastornos, como ansiedad, dislexia, discalculia o trastorno negativista desafiante (Departamento de Educación del Gobierno de Navarra, 2001).

\section{METODOLOGÍA}

Para lograr los objetivos del presente trabajo se ha llevado a cabo un estudio empírico de tipo cualitativo y descriptivo (León y Montero, 2015) en el que se presenta un repositorio de las principales aplicaciones existentes para el trabajo con alumnos de diversas discapacidades, analizando sus ventajas y desventajas. La metodología que se ha utilizado se basa en un diseño centrado en los alumnos con diversos tipos de discapacidad y en los docentes como usuarios potenciales del repositorio. El procedimiento se ha llevado a cabo mediante las siguientes fases, que corresponden a los diferentes epígrafes del desarrollo del presente trabajo:

- Fase I. Recopilación de herramientas. Se han buscado en internet y en artículos especializados todas aquellas herramientas tecnológicas que pudieran ser utilizadas en el proceso de enseñanza-aprendizaje de los alumnos de cada discapacidad concreta. Para esta fase se han utilizado las siguientes palabras clave como criterio de búsqueda: discapacidad, aplicaciones tecnológicas y enseñanza-aprendizaje.

- Fase II. Descripción de los resultados de la búsqueda. Se han descrito las herramientas que se han encontrado y se han clasificado de acuerdo a sus características. Asimismo, se ha seleccionado la herramienta más importante y con mayor relevancia en el proceso de enseñanza-aprendizaje para continuar con las siguientes fases.

- Fase III. Análisis de la herramienta seleccionada para cada tipo de discapacidad. Se han analizado detalladamente las herramientas seleccionadas en la fase II, cómo funcionaban, en qué consistían y sus principales ventajas y limitaciones. 
- Fase IV. Propuesta de implementación. Se ha realizado una propuesta completa de implementación de la herramienta seleccionada en un aula concreta. Dicha propuesta se ha presentado de forma completa, incluyendo cronograma y actividades programables en la herramienta.

\section{DESARROLLO}

\subsection{Fases I y II. Recopilación de herramien- tas y descripción de los resultados de la búsqueda}

En la actualidad se han desarrollado diversidad de programas y aplicaciones que pueden ser útiles para la enseñanza y el aprendizaje de alumnos con discapacidad y que están orientados a mejorar, desarrollar o modificar aquellos ámbitos en los que presentan alteraciones. Es un campo que se encuentra en continuo crecimiento y actualización y, por ello, es prácticamente inabarcable en su totalidad. A continuación, y sin ánimo de exhaustividad, se presenta un repositorio de herramientas que pueden ser útiles en el proceso de enseñanza-aprendizaje de alumnos con discapacidad motriz, autismo y TDAH.

\subsubsection{Discapacidad motriz}

Muchos de nuestros alumnos no poseen habilidades motrices básicas que les posibiliten el acceso a las herramientas TIC a través de los periféricos y configuraciones estándares. Es por ello que a continuación se presentan las herramientas TIC esenciales que promueven el uso progresivamente autónomo de los medios audiovisuales por parte de alumnos con discapacidad motora, visual y auditiva. Por medio de la búsqueda y de la selección de las herramientas informáticas (software y hardware) más eficaces y completas, presentamos una clasificación propia, resaltando las más adecuadas y siguiendo las recomendaciones de García Ponce (2011) y Santos (2012).

\section{A) Software}

Atendiendo a la adaptación del software, diferenciamos los sistemas operativos:
- Windows. A través de Microsoft, este sistema operativo pone al alcance de las personas con discapacidad diferentes opciones de adaptación, accediendo desde Panel de control (algunas conllevan un coste adicional). Entre ellas podemos contar con voz, lupa, teclado en pantalla, narrador y notificaciones visuales. Asimismo, Windows ofrece algunas herramientas software desarrolladas para la adaptación de los elementos del ordenador. Algunos ejemplos son Jaws for Windows, que es el lector de pantallas más conocido; FilterKeys, que evita pulsaciones repetidas si los usuarios presentan dificultades motrices, favoreciendo su precisión para acceder al inicio, al panel de control, a las opciones de accesibilidad y al teclado; y MouseKeys, que permite controlar los movimientos del ratón a través del teclado numérico de nuestro ordenador.

- Apple. Pone a nuestro alcance varias opciones de accesibilidad para personas con discapacidad sin coste adicional, como, por ejemplo, la ampliación de pantalla, una interfaz simplificada que favorece la exploración y el aprendizaje, teclas para el ratón, teclas lentas y de pulsación fácil, braille en espejo, lector de pantalla mediante gestos, subtítulos de películas y VoiceOver, que es una herramienta desarrollada para iOS que funciona como un lector de pantalla controlado por gestos y que te permite interaccionar, aunque no puedas ver la pantalla.

- Linux. Nos ofrece varios proyectos dedicados a mejorar la accesibilidad de personas con discapacidad, de los que los más importantes son el proyecto KDE, que permite personalizar todos sus componentes, configurándolos mediante una licencia de software libre (gestión de composición de ventanas, gestión de archivos, información personal, comunicaciones, integración de otros dispositivos, etc.), y el proyecto

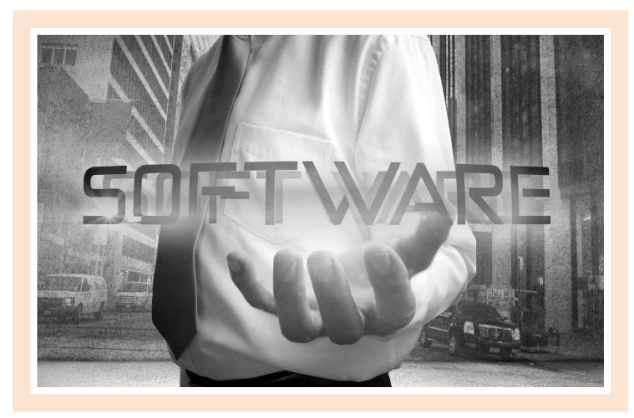


GNOME, que es una alternativa al proyecto anterior, también de software libre, que muestra un gestor de ventanas intuitivo y eficiente y una plataforma de desarrollo para crear aplicaciones que se integran con el escritorio.

Existen diversas aplicaciones informáticas programadas que pueden ser muy útiles para las personas con discapacidad motriz:

- Kanghooru. Ratón virtual que permite manejar los programas mediante un pulsador, realizando un barrido que previamente ha sido definido con el propio programa.

- Screen Scanner. Barre la pantalla de manera vertical y horizontal, detectando las zonas activas y posibilitando ingresar en cada una de ellas.

- Boardmarker. Herramienta de comunicación aumentativa y/o alternativa que permite el acceso a cliparts del sistema pictográfico de comunicación (SPC), así como crear paneles de comunicación personalizados configurando espaciado, tamaño, etc.

- Plaphoons. Esta aplicación es parecida a la anteriormente descrita, ya que también posibilita crear paneles de comunicación sencillos e intuitivos, añadir sonido, etc.

- ARASAAC. Portal web en el que podemos encontrar generadores de material de soporte lingüístico diverso (creador de animaciones, símbolos, frases, horarios, calendarios, tableros, bingos, etc.) con el fin de favorecer el aprendizaje, la comunicación y el análisis de la realidad de nuestros alumnos y software específico para alumnos con NEE (acceso a internet, al ordenador, agendas visuales, procesadores de texto, aplicaciones móviles, etc.).

- MAGic. Selecciona y amplía las partes que se desean leer de un texto.

- ZoomText Xtra. Posibilita ampliaciones de gráficos.

- Supernova. Permite la ampliación de pantalla, su lectura y conversión a braille.

- Open Book. Escanea y lee documentos.

- Preditext. Herramienta de apoyo a la escritura que automatiza los procesos predictivos en cualquier aplicación Windows que tenga el foco activo. Predice palabras, las completa, presenta una lista de palabras nuevas sugeridas, reorganiza el sistema según las palabras más utilizadas, etc.
Entre las aplicaciones didácticas destacables, mencionamos:

- Sen Switcher. Está compuesto por 132 actividades distribuidas en siete fases, que abarcan desde aspectos de estimulación visual y auditiva, hasta el aprendizaje de la relación causa-efecto.

- LaMosqueta.cat. Juegos adaptados al pulsador Calcwav: calculadora parlante, que va diciendo en voz alta las operaciones que se van realizando. De esta forma se favorece la utilización de las calculadoras para las personas que presentan una discapacidad motriz y visual.

- Platets Voladors. Es un juego que permite manejar el ratón a personas con movilidad reducida, quienes intentarán vencer a los platillos volantes que aparecen en la pantalla.

- Control de juegos por escaneo de teclado. Descargable desde Proyecte Fressa, permite controlar programas mediante barrido automático haciendo clic en el ratón o en algún pulsador.

- Actividades zonaClic. Acceso a un listado de aplicaciones y juegos didácticos de diversas temáticas y adaptaciones.

\section{B) Hardware}

Respecto a la adaptación del hardware, distinguimos los elementos físicos esenciales para que el ordenador funcione. Refiriéndonos a la torre, al monitor y al teclado, existen pulsadores mini-sling, interruptores o sensores especiales que favorecen su uso por parte de personas que presentan discapacidad motriz, ya que posibilitan el ajuste de sensibilidad para las distintas partes del cuerpo afectadas.

Concretamente, al tratar de teclados adaptados nos estamos refiriendo a los siguientes:

- Teclados reducidos. Presentan tamaños reducidos con una menor amplitud de movimientos.

- Teclados ampliados. Son de tamaño mayor que los convencionales para favorecer la falta de precisión de personas con discapacidad motriz.

- Teclados agrandados. Teclados QWERTY con menos teclas que un teclado convencional, pero de mayor tamaño. 


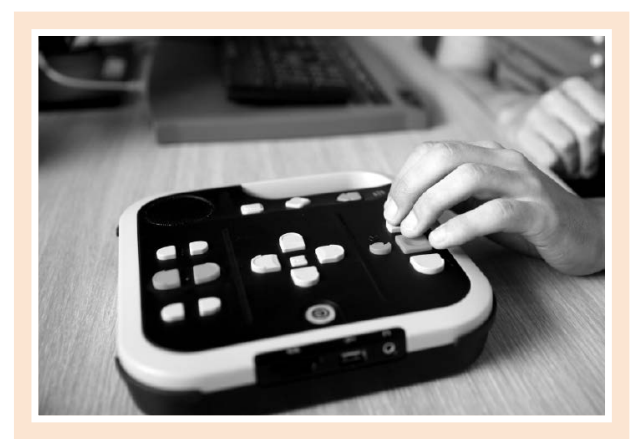

- Teclados programables. Teclados configurables según las necesidades de los usuarios a través de diversas láminas flexibles.

- Teclados para una sola mano. Muestran una disposición especial para promover el uso de una única mano.

- Teclados especiales. Presentan una distribución estratégica para la colocación de las manos y tienen el ratón incorporado.

- Teclados por pedales. Dispositivos programables a través de tres botones, que se pueden simultanear con un teclado estándar.

- Teclados de conceptos. Teclados que muestran 128 casillas con acciones relacionadas a cada una.

- Licornio. Casco al que se puede adjuntar un puntero o lápiz para su uso gráfico.

- Carcasa. Estructura de metacrilato que asegura la pulsación de una tecla sin presionar las demás circundantes por falta de precisión y destreza motriz.

Los ratones también presentan múltiples variedades de adaptación, como mostramos a continuación:

- Ratón controlado por botones. A través del uso de las teclas, actúa según distintas presiones y velocidades.

- Ratón activado por láser. Ratón adaptado que funciona mediante el efecto del láser sobre una carcasa de plástico.

- Ratón externo de barrido. Funciona mediante 13 luces que se encienden dependiendo de las franjas horarias.

- Ratones joystick. Presentan una forma ergonómica que favorece su uso por personas de movilidad reducida.
- Ratones magnificados. Posibilitan una mayor precisión de los movimientos ante las dificultades motrices.

- Emulador de ratón por pulsadores. Permite la simulación de los movimientos del ratón sobre la mesa recurriendo a pulsadores.

- Ratón ergonómico. Su funcionamiento dista del de un ratón convencional porque la mano con la que se maneja debe colocarse perpendicular a la mesa.

- Ratón por sensores ópticos. Realizan los desplazamientos deseados captando los movimientos que los usuarios realizan con la cabeza.

- Ratones de boca. Los desplazamientos se realizarán captando los soplos, las aspiraciones o los movimientos de la boca que detecte el ratón.

- Ratón para barbilla. Funciona a través de un joystick que percibe los movimientos de barbilla que realizan los usuarios para ejecutar los desplazamientos del ratón.

- Ratones PAD. Destinados a personas con dificultad motriz pero que puedan realizar movimientos con un dedo que maneje el ratón.

- Ratones adaptados para pulsadores. Son ratones convencionales adaptados para su uso con cualquier tipo de pulsador con conexión jack estándar.

\subsubsection{Autismo}

Actualmente existen diversas herramientas TIC de apoyo para el alumnado con autismo. Estas herramientas se pueden clasificar de acuerdo al área que se trabaja, encontrando así herramientas para la comunicación (sistemas aumentativos y alternativos de comunicación [SAAC]), herramientas de navegación e interacción, herramientas para el desarrollo de las habilidades sociales y emocionales y programas de estructuración ambiental. Por otro lado, existen otras aplicaciones que engloban diversas dimensiones en las que trabajar y atienden a las características y necesidades de este tipo de alumnado.

En tabla 2 se recogen aplicaciones y programas para trabajar con alumnos que tienen autismo, cuyos criterios de selección han sido su frecuencia de aparición en webs y artículos especializados, su facilidad de acceso, instalación y uso, su disponibilidad en castellano y su carácter gratuito o con un precio muy bajo. 


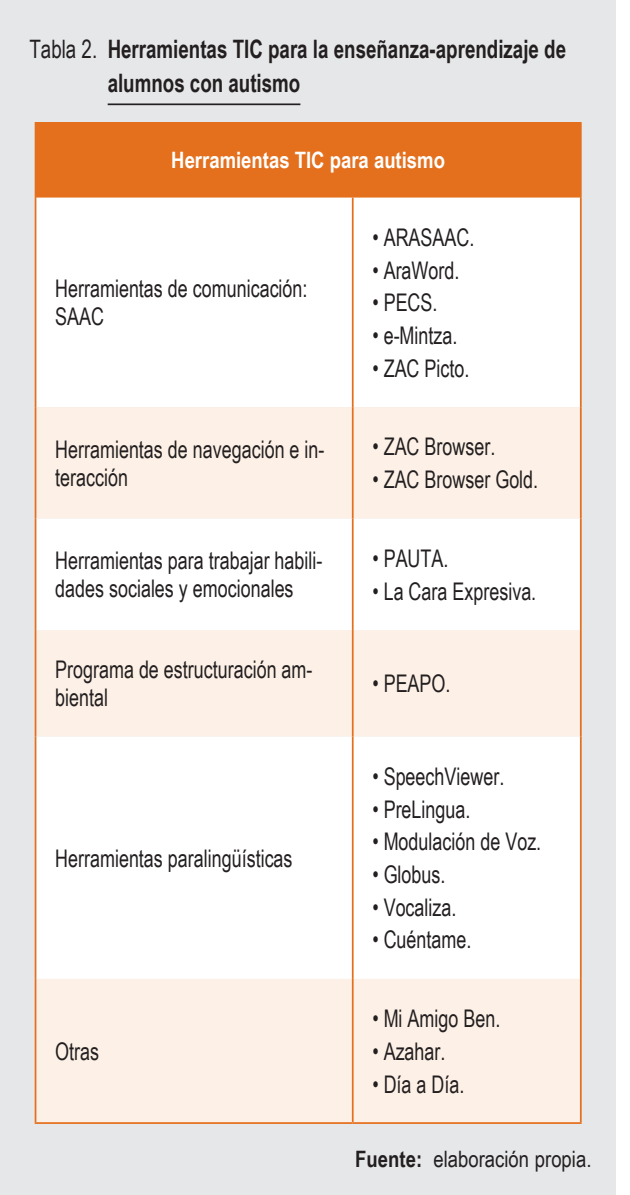

A continuación explicamos las características de cada una de las herramientas TIC para la enseñanza-aprendizaje de alumnos con autismo:

- Herramientas para la comunicación: SAAC. Los SAAC son instrumentos de intervención logopédicoeducativos destinados a personas con alteraciones diversas de la comunicación y/o del lenguaje, cuyo objetivo es la enseñanza mediante procedimientos específicos e instrucción de un conjunto estructurado de códigos no vocales, los cuales permiten funciones de representación y sirven para llevar a cabo actos de comunicación.

- Herramientas de navegación e interacción. Este tipo de herramientas están desarrolladas específicamente para niños con TEA, ya que permiten que

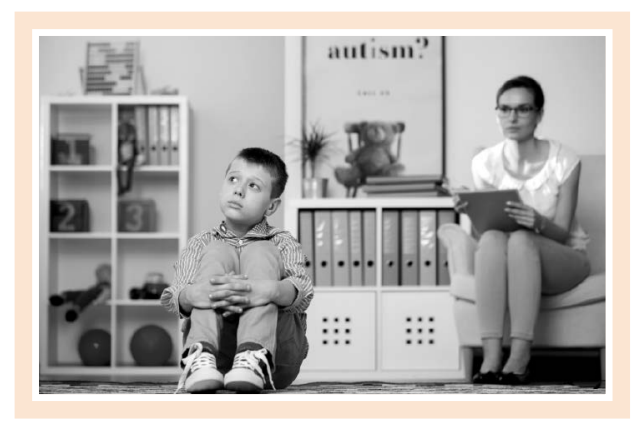

puedan navegar e interactuar de forma segura, al mismo tiempo que favorecen su autonomía. El portal ZAC Browser fue el primer navegador web y espacio virtual desarrollado específicamente para niños con TEA. Fue creado por John LeSieur, ya que tras conocer que su nieto Zackary tenía autismo, reorientó su carrera profesional en el campo de la informática y la enfocó en desarrollar aplicaciones para facilitar la vida a las personas que tienen este trastorno y a quienes les rodean. Con este navegador se bloquean algunas teclas y funciones a la hora de acceder a internet con el fin de evitar que el niño con autismo se distraiga con funciones secundarias. Este programa presenta un filtro que bloquea contenidos violentos, sexuales o para adultos. Utiliza comunicación no verbal, basada en imágenes y pictogramas, tan útiles en su interacción y comunicación, y no existen opciones de texto como requisito para la navegación.

- Herramientas para el desarrollo de habilidades sociales y emocionales. El reconocimiento de expresiones faciales y la simulación de contextos sociales en un mundo virtual son ejemplos de aplicaciones que ayudan a desarrollar en las personas con autismo habilidades sociales y emocionales, esenciales para la interacción social y el entorno que les rodea.

- Programas de estructuración ambiental. Esta clase de programas de estructuración ambiental están orientados a la mejora de las capacidades de aut odirección de las personas con algún TEA.

- Herramientas paralingüísticas. Son herramientas y aplicaciones TIC con las que trabajar la prosodia y aspectos como el tono de voz, la velocidad del habla, la regulación o la intensidad de la voz, etc.

- Otras. Dentro de este grupo se incluyen distintas herramientas y aplicaciones que abordan diferentes facetas, desde juegos interactivos para el aprendi- 
zaje cognitivo, hasta aquellas que favorecen la autonomía, como la elaboración de agendas y calendarios interactivos.

Además de la clasificación arriba descrita, cabe mencionar, tal y como apunta Kano (2013), que otra herramienta con unas posibilidades incríbles para la intervención y la mejora de la comprensión de las personas con TEA y su procesamiento de la información es la realidad virtual, pero su uso no es de fácil generalización, lo que sí ocurre con los portales web. Existen variedad de portales que facilitan la enseñanza de este tipo de alumnado. Uno de los más conocidos y completos es el portal aragonés ARASAAC, ya mencionado anteriormente en el epígrafe de discapacidad motriz, el cual ofrece una gran variedad de recursos gráficos y materiales para facilitar la comunicación de aquellas personas con algún tipo de dificultad en esta área. ARASAAC está especializado en recursos TIC para el profesorado que trabaja con alumnado que usa los SAAC. Es muy útil para personas con autismo, pues sirve para que realicen con pictogramas sus rutinas diarias. Por otro lado, cabe destacar la labor de la Fundación Orange, que apuesta de manera fehaciente por el uso de la tecnología para ayudar a mejor la calidad de vida de las personas con TEA. Esta fundación ha realizado diferentes proyectos con la colaboración de empresas, expertos, universidades y asociaciones de usuarios, cuyos resultados han sido una variedad de aplicaciones y portales, entre los que se encuentran In-TIC, e-Mintza, Día a Día, Soy Visual, PictoRoom o José Aprende.

\subsubsection{TDAH}

Al igual que en los casos de discapacidad motriz y autismo, existen numerosas herramientas tecnológicas con las que poder abordar diferentes aspectos con los niños que presentan TDAH en el aula. Los 31 recursos que se muestran en la tabla 3 están agrupados en categorías según las áreas que se pueden trabajar con el alumno.

\subsection{Fase III. Análisis de la herramienta se- leccionada para cada tipo de disca- pacidad}

\subsubsection{Discapacidad motriz}

En el caso de la discapacidad motriz se ha seleccionado, para profundizar, el teclado de conceptos IntelliKeys. El teclado de conceptos, y más concretamente

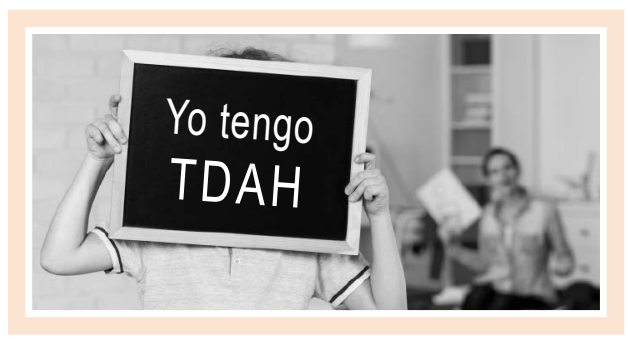

Tabla 3. Herramientas TIC para la enseñanza-aprendizaje de alumnos con TDAH

\begin{tabular}{|c|c|}
\hline \multicolumn{2}{|c|}{ Herramientas TIC para TDAH } \\
\hline Neurofeedback & $\begin{array}{l}\text { - Unobrain. } \\
\text { - Play Attention. }\end{array}$ \\
\hline Multidisciplinar & - Entorno Digital. \\
\hline $\begin{array}{l}\text { Concentración y } \\
\text { atención }\end{array}$ & $\begin{array}{l}\text { - Games for the Brain. } \\
\text { - Rompecabezas. } \\
\text { - Máquina de Calcular. } \\
\text { - Juegos para la Atención. } \\
\text { - Stay Focused. }\end{array}$ \\
\hline Específicas para TDAH & $\begin{array}{l}\text { - TDAH Trainer. } \\
\text { - ActiviBox. } \\
\text { - MeMotiva. } \\
\text { - Javle. }\end{array}$ \\
\hline $\begin{array}{l}\text { Coordinación, atención, ra- } \\
\text { pidez y concentración }\end{array}$ & $\begin{array}{l}\text { - Siluetas OA. } \\
\text { - TwisTouch. } \\
\text { - Touch the Numbers. } \\
\text { - Smack that Gugl. } \\
\text { - Count Battle. } \\
\text { - Voice Dream. }\end{array}$ \\
\hline $\begin{array}{l}\text { Memoria visual y } \\
\text { auditiva }\end{array}$ & $\begin{array}{l}\text { - Memorama. } \\
\text { - Match Game. } \\
\text { - Memory Trainer. } \\
\text { - Improve your Memory. } \\
\text { - Busca las Diferencias. } \\
\text { - Simon. } \\
\text { - No Hay Dos Iguales. } \\
\text { - Visual Attention. }\end{array}$ \\
\hline $\begin{array}{l}\text { Razonamiento espacial, ló- } \\
\text { gica, estrategias y } \\
\text { anticipación }\end{array}$ & $\begin{array}{l}\text { - Tangram. } \\
\text { - Move the Box. } \\
\text { - Proyecto Habilidades. } \\
\text { - Amazing Brain. } \\
\text { - Álex Aprende a Ordenar. }\end{array}$ \\
\hline
\end{tabular}

Fuente: elaboración propia. 
IntelliKeys, es un periférico adaptado y conectado al ordenador mediante conexión USB (universal serial bus) para permitir su uso a alumnos y adultos que poseen necesidades motrices. Presenta láminas intercambiables en las que aparecen multitud de casillas con opciones relacionadas; algunas, más concretas y personalizables, y otras, de uso genérico sobre el manejo del teclado, seleccionar opciones del menú o navegar por la pantalla. Sobre estas láminas hemos de indicar que el teclado incluye una plantilla de configuración y seis predeterminadas, pero, además, mediante el uso del programa Overlay Maker, es posible diseñar plantillas personales para su uso.

El teclado de conceptos IntelliKeys está disponible para Windows desde la versión 98 y es compatible con otros softwares educativos, como cualquier teclado ordinario. Ofrece una ergonomía ligera y reducida $(44 \times 26 \mathrm{~cm})$, por ello se puede trasladar a distintos entornos $y$ facilitará su uso en varias aulas y por diversidad de alumnado, docentes, etc. A partir de sus características técnicas podemos deducir algunas de las ventajas didácticas que promueve, como, por ejemplo:

- Agrupar y clasificar las teclas o casillas según criterios específicos y convenientes adaptados a las temáticas de los aprendizajes y a la evolución de los alumnos. Esta personalización posibilita crear contrastes de colores, tamaños y espacios entre las diferentes secciones del teclado para un uso más intuitivo y sencillo por parte de los alumnos con dificultades motrices.

- Las plantillas personalizables permiten la sustitución numérica y alfabética de los teclados ordinarios por dibujos esquemáticos o pictogramas que mejoren la comprensión ante dificultades lectoras, visuales, etc.

- La adaptación individualizada permite conectar fácilmente con los intereses y necesidades de los alumnos.

- Favorecen la concentración y la evolución en la adquisición de conceptos.

No obstante, también posee algunas limitaciones que se podrían mejorar en un futuro para que fuera aplicable a otros sistemas operativos como Linux, Android o iOS (en estos últimos casos sería de utilidad como complemento a las tablets). Es necesaria la adquisición de láminas en acrílico para proteger y alargar la duración de las plantillas adaptables durante su uso, y las destre- zas de los docentes con la herramienta Overlay Maker será conveniente para la creación de plantillas adaptadas a los procesos de enseñanza-aprendizaje. Además, es indispensable la instalación de la suite educativa IntelliTools; requiere equipos con características técnicas específicas, como espacio en el disco duro (160 MB), espacio de RAM mínimo (desde 64 MB-128 MB, según la versión de Windows de la que dispongamos en el equipo) y resolución de colores en pantalla de 16 bits; se necesita CD-ROM para su ejecución; no ejecuta sonido, y no presenta accesibilidad por medio de interruptores más allá de su conexión al ordenador.

Por último, a pesar de que el teclado de conceptos IntelliKeys es la herramienta destacada, consideramos oportuno realizar una breve mención al programa Overlay Maker por ser de gran utilidad para la creación de plantillas de conceptos en este tipo de teclados. Overlay Maker es una herramienta de software que permite crear plantillas para estos teclados IntelliKeys. Posibilita su elaboración y configurar los teclados por parte de los usuarios o profesionales (en este caso, profesores), permitiendo que el alumno con discapacidades se pueda adaptar más rápidamente. La herramienta Overlay Maker funciona descargándola en el ordenador. Una vez descargada podemos crear plantillas según nuestras preferencias, organizando la localización de teclas y flechas para realizar acciones como abrir el correo, apagar el ordenador, reproducir audio y ordenar teclas importantes, como Enter, Esc, Espacio, etc. Posteriormente imprimimos la plantilla creada y configuramos el teclado IntelliKeys encajando la fotocopia dentro del dispositivo.

\subsubsection{Autismo}

En el caso de los alumnos con autismo se ha seleccionado, para profundizar, la aplicación Día a Día. Se trata de una aplicación que permite realizar agendas de actividades para personas con autismo, guardando y revisando lo que se ha hecho de forma gráfica y estructurada. La aplicación permite anticipar actividades o eventos recurrentes en el tiempo que ya han sido realizados y que se han anotado en la misma, fomentando la comunicación a través de las actividades. Se trata de una herramienta que da mucha relevancia a los elementos visuales, ofreciendo distintas opciones de personalización. Para la utilización de esta herramienta se 
requiere una tablet o teléfono inteligente con sistema Android o iOS 6.0 o posterior. Una vez que la herramienta se ha descargado en el dispositivo, se accede a la página principal, donde aparece un menú en el que se encuentran tres iconos a los que se puede acceder (personas, lugares y calendario). La página de inicio se puede personalizar subiendo una imagen del usuario.

Si se accede al menú Calendario, se puede ver un sencillo calendario en el que es posible visualizar los meses, las semanas, los días e incluso está dividido en mañana, tarde y noche. Esta misma pantalla nos da la posibilidad de crear eventos en el mes y en el día que se desee. Dentro de la creación de la actividad se puede configurar un evento en función del momento del día (mañana, tarde o noche), incluir el título del evento, fotografías, audio, vídeos, lugares y personas. Las otras dos pestañas de la pantalla de inicio dan la posibilidad de ver a las personas con las que se ha acudido a las actividades, así como los lugares que se han visitado.

Entre las ventajas que ofrece la herramienta destacan que es una aplicación gratuita, sencilla e intuitiva, que cuenta con la posibilidad de compartir información y actividades a través de correo electrónico y que tiene soporte para Android e iOS 6.0 y posteriores. Sus principales limitaciones son que no se puede sincronizar con otros dispositivos y que está disponible en pocos idiomas (castellano, catalán e inglés).

La elección de esta herramienta se justifica en que los diarios y las agendas constituyen un elemento imprescindible para el alumnado con autismo, ya que les permite organizar el mundo que les rodea explicándoles qué van a hacer, cuándo, cómo, dónde y con quién. También les ofrece una visión clara de cómo moverse en los espacios, ganando así independencia. Las personas con autismo presentan dificultades en la secuenciación temporal, dificultad en la recepción de órdenes verbales, dificultades de atención, etc. A través de estos elementos se trabaja la flexibilidad, se promueve la independencia y se facilita la transición de tareas. Estas herramientas deben ser visuales y ayudar al alumnado a diferenciar entre las actividades de la jornada y anticipar y predecir actividades. Se utilizan en múltiples ocasiones a lo largo de la jornada, pero es determinante el uso a primera hora, cuando se van a planificar las actividades que se llevarán a cabo durante todo el día. Constituyen una forma sistemática y visual para aclarar al alumnado determinadas cuestiones. Los sistemas de trabajo con agendas y diarios se fundamentan en los principios de enseñanza estructurada, la cual se basa en usar apoyos visuales para aprovechar este estilo de aprendizaje tan efectivo en el alumno con autismo.

\subsection{3. $T D A H$}

En el caso de los alumnos con TDAH se ha seleccionado, para profundizar, la técnica de neurofeedback. El neurofeedback o retroalimentación electroencefalográfica es un método para el entrenamiento de la función cerebral, de carácter individual y destinado a la adquisición del autocontrol mediante patrones de actividad. Es monitorizado por un terapeuta que se encarga de colocar electrodos en la cabeza del sujeto y en los lóbulos de las orejas, funcionando como sensores para transmitir la información de las acciones cerebrales. A través de un programa informático en tiempo real se miden los niveles de resonancia cerebral utilizados y se genera una puntuación según el nivel de atención del sujeto. Esta técnica es óptima para tratar el TDAH, pero también sirve para paliar otras afecciones como el estrés, las migrañas, la ansiedad, la tensión muscular, el dolor crónico o el insomnio (Gaitán, 2015). Es una técnica indolora e inofensiva, sin efectos secundarios, por lo que en muchas ocasiones se utiliza como sustitutivo de la medicación y, además, es algo que resulta entretenido para el niño. Por su parte, los efectos o resultados que se obtienen son permanentes, ya que las redes neuronales que se crean con su entrenamiento no se vuelven a destruir, y su formato se asemeja al de un videojuego.

Existen dos tipos de intervenciones con neurofeedback, según el tipo de onda cerebral en la que se concentran. Las ondas beta tienen un ritmo de entre 20 y 30 hercios y están relacionadas con el estado de atención de una persona, por eso son las que se estudian en la mayoría de entrenamientos con este método. La amplitud de estas ondas aumenta cuando las áreas sensoriomotrices están inactivas y disminuye cuando se activan. Otros estudios tienen como objeto los potenciales corticales lentos, que se producen ante ciertas tareas mentales e indican la activación de partes de la corteza cerebral (Cruz, 2012). Este tratamiento para niños con TDAH se basa en el llamado "condicionamiento operante» 0 «instrumental», que sostiene que una determinada conducta que lleve a una determinada consecuencia produce aprendizaje (Mae, 2011). El neurofeedback es un aprendizaje gradual que se trabaja en varias sesiones, 
las cuales suelen oscilar en torno a 8 o 10, dependiendo de las características del niño, de los progresos y de los resultados. Al comienzo del entrenamiento se suelen desarrollar sobre 2-3 sesiones por semana y, conforme se va avanzando, se reducen, dejando más espacio entre una y otra. Los entrenamientos con este método a largo plazo generan beneficios en el niño con TDAH, como el aumento en el ritmo de aprendizaje; la mejora de la memoria; el aumento de la capacidad de concentración; la mejora en la gestión del estrés; la superación del miedo al fracaso; la mejora en la velocidad de procesamiento, en las actividades artísticas o visoespaciales y en las actividades deportivas; el aumento de la motivación y el interés; la mejora en plasticidad neuronal, y la mejora global de todas las funciones cognitivas. En cuanto a sus inconvenientes, el único que podemos concluir es el alto coste de su adquisición.

En la red nos encontramos con dos ejemplos de herramientas que se basan en esta técnica:

- Unobrain. Es una página web de un club online que se dedica a entrenar el cerebro de sus usuarios mediante juegos. Ofrece 7 programas con más de 50 juegos cada uno que trabajan la memoria, la atención, la percepción, el lenguaje y la velocidad mental. Cuenta con un módulo en el que se muestran los progresos de cada persona y la comparación con otros usuarios. Para que se lleve a cabo el método del neurofeedback en su totalidad es necesario utilizar los cascos específicos que la propia web tiene en venta, aunque cabe la posibilidad de realizar las actividades eludiéndolos. El acceso a las posibilidades que ofrece hace necesario el registro. A partir de ahí, tendremos a nuestra disposición juegos gratuitos o de pago, si se decide comprar la versión premium. En el registro se debe seleccionar el nivel de estudios, para que, automáticamente, los juegos sean acordes a la edad del usuario. La web está dividida en tres partes (Brain Training, Control de Estrés y Ejercicio y Nutrición) que están compuestas de diferentes actividades (Unobrain, 2016).

- Play Attention. Es otra herramienta de pago basado en el neurofeedback, cuyo objetivo es mejorar la concentración y la atención de las personas desde los 5 años a través de diferentes juegos que trabajan habilidades específicas. Si durante el juego el usuario pierde la atención, el juego se para, mientras que si progresa adecuadamente, se le recompensa, siendo de carácter adaptativo. La técnica utilizada está basada en los entrenamientos desarrollados por la National Aeronautics and Space Administration (NASA) y por la Fuerza Aérea de EE. UU. (Hodges, s. f.), entre otros, y utiliza la tecnología BodyWare para registrar los progresos. Esta herramienta es un brazalete que trasfiere la información cerebral del usuario a un ordenador a través de Bluetooth continuamente y se complementa con un software informativo $y$ administrativo en el que se elaboran todo tipo de documentos relacionados con las sesiones que se llevan a cabo, como seguimiento, mejoras, problemas, etc. Se recomienda realizar en torno a 40060 entrenamientos para lograr unos resultados exitosos, divididos en 1 hora semanal, preferiblemente realizando dos sesiones de 30 minutos, estableciendo un horario más o menos fijo. El sistema se puede adquirir para uso particular o para centros educativos y viene con un hardware en forma de brazalete para monitorizar las ondas cerebrales mientras se juega. Además, cuenta con una herramienta llamada SRS (session rating scale) a través de la que se puede consultar la información acerca de los progresos en cada una de las sesiones. Existen dos tipos de sistemas Play Attention a la hora de realizar la compra: el formato común o el formato iLab, para realizar el entrenamiento en grupos controlados por un instructor, especialmente diseñado como un laboratorio interactivo para centros educativos (Nascia, 2016).

\subsection{Fase IV. Propuesta de implementación}

A pesar de la existencia de aplicaciones y programas TIC para el apoyo de los alumnos con discapacidad se han encontrado pocas investigaciones en las que se haya llevado a cabo un implementación de herramientas TIC en el aula. Es por ello que el presente trabajo plantea las siguientes propuestas educativas de aplicación de herramientas TIC en alumnos con cada una de las discapacidades trabajadas.

\subsubsection{Contexto del colegio en el que se reali- zan las propuestas de implementación}

La implementación se propone para un centro de educación pública de infantil y primaria de la zona norte de Madrid. Se encuentra dotado con personal de todas las etapas y especialidades, así como con docentes de 
apoyo (véase tabla 4). En el primer ciclo de primaria el alumnado aún se encuentra afianzando algunos conceptos y destrezas en la comunicación oral y escrita y es por este motivo por el que resulta interesante abordar el proyecto por medio de las herramientas anteriormente descritas, como ampliación para los alumnos y apoyo a los niños con discapacidad. Además, el desarrollo de estas estrategias comunicativas sigue la línea de trabajo propuesta en la programación general anual del centro educativo objeto de la intervención. Asimismo, dicha programación fomenta el uso de las nuevas tecnologías para mejorar y adaptar los procesos de enseñanza-aprendizaje. El colegio posee instalaciones exteriores e interiores variadas (polideportivo, sala de usos múltiples, patios acondicionados, sala de profesores, sala de informática y recursos TIC en todas las aulas, etc.). Es un centro preferente de alumnos con discapacidad y toda la comunidad educativa se encuentra muy involucrada en la adaptación del proceso de enseñanza-aprendizaje, potenciando el uso de las TIC. Nuestra programación tiene como destinatarios un grupo de 23 niños de $3 .^{\circ}$ de educación primaria. Tienen una edad media de 8 y 9 años, en general; es un grupo heterogéneo y los niños presentan independencia y autonomía acorde a su edad. Contamos con interculturalidad en el aula y con la presencia de alumnos con NEE que requieren un seguimiento especial para atender a sus necesidades específicas de apoyo educativo.

Tabla 4. Características del colegio para la integración de alumnos con discapacidad motriz

\begin{tabular}{|c|c|}
\hline \multicolumn{2}{|c|}{ Características } \\
\hline Número de unidades & $\begin{array}{l}\text { - Infantil (6). } \\
\text { - Primaria (12). }\end{array}$ \\
\hline Número de alumnos & $\begin{array}{l}\text { - Total (108). } \\
\text { - Con NEE (16). }\end{array}$ \\
\hline Especialistas & $\begin{array}{l}\text { - Música (1). } \\
\text { - Educación Física (2). } \\
\text { - Inglés (6). }\end{array}$ \\
\hline Profesores de apoyo & $\begin{array}{l}\text { - Pedagogía terapéutica (1). } \\
\text { - Audición y lenguaje (1). }\end{array}$ \\
\hline
\end{tabular}

Fuente: elaboración propia.

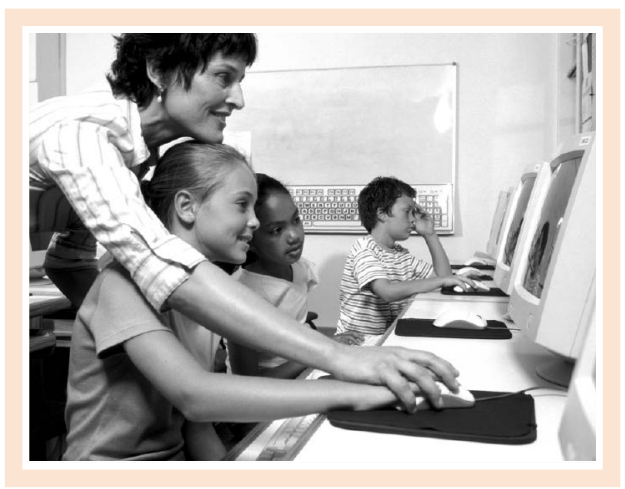

\subsubsection{Objetivos de la propuesta de implemen- tación}

El objetivo general que se plantea con las propuestas de implementación es que los niños con discapacidad tengan una integración plena en el aula, así como el desarrollo de habilidades de aprendizaje por medio de actividades lúdicas, motivadoras y relacionadas con el uso de las herramientas tecnológicas propuestas.

Concretamente, entre los objetivos docentes de la propuesta, definimos:

- Describir una propuesta de implementación de las herramientas TIC en un proceso de enseñanzaaprendizaje presencial que persigue la inclusión de alumnos con NEE.

- Plantear medidas ante las problemáticas que puedan surgir cuando los alumnos con NEE realicen actividades.

- Resaltar la importancia de las herramientas TIC como elementos de inclusión y desarrollo en la propuesta didáctica.

- Mejorar la calidad del proceso educativo que se promueve hacia los alumnos con NEE gracias a la incorporación de las TIC en el aula.

Como objetivos del proceso de aprendizaje, identificamos:

- Reconocer la secuencia temporal de una narración sirviéndose de representaciones multimedia.

- Desarrollar formas de expresión oral, escrita y audiovisual. 
- Utilizar la lectura como medio para ampliar vocabulario y fijar la ortografía correcta.

- Emplear recursos tecnológicos para estructurar la información.

- Utilizar la lectura como fuente de disfrute, información y enriquecimiento personal.

- Ordenar la secuencia temporal de una narración a través de pictogramas creados por ordenador.

- Inventar historias utilizando recursos TIC.

- Sintetizar información relevante en una narración por medio de soporte tecnológico.

- Escenificar una historia a través de la expresión corporal, plástica, oral y audiovisual.

- Interesarse por la lectura como medio de disfrute y conocimiento.

- Consultar páginas web relacionadas con los cuentos.

\subsubsection{Intervención en un niño con discapaci- dad motriz}

A continuación se plantea la secuenciación de 10 talleres sobre cuentos y relatos en la asignatura Lengua Castellana (en nuestro caso, tuvo lugar a lo largo del segundo trimestre escolar del curso 2016/2017). Dicha secuenciación está encaminada a trabajar la lectura, la escritura, la expresión y la comprensión de la misma en $3 .^{\circ}$ de educación primaria, en concreto con un niño que tiene discapacidad motriz. A continuación, detallamos algunas características del alumno con discapacidad motriz para entender mejor qué consideraciones, estrategias y técnicas deberemos aplicar en la propuesta para adaptarnos a sus ritmos y necesidades. El alumno presenta un tipo de discapacidad motriz con afectación cerebral, denominada «atetosis». Afecta al control y a la coordinación de los movimientos y, por lo tanto, supone un retraso madurativo globalizado en todas las áreas del desarrollo. El desfase entre la edad cronológica y la edad de desarrollo podría situarse en torno al año de edad. Además, el alumno presenta episodios de epilepsia controlados bajo medicación, pero que requerirán adaptaciones generales en la estructuración del tiempo e interacción verbal para combatir las ausencias que sufre. Sobre las necesidades educativas que presenta, destacamos entre las distintas áreas:

- Lenguaje. Inhibición y pausas prolongadas en lenguaje con los iguales y adultos, a veces provocadas por los movimientos lentos de los músculos bucales y las ausencias sufridas a causa de la epilepsia, que le impiden seguir el ritmo ordinario. En el lenguaje escrito debe seguir desarrollando la conciencia fonológica y en el trazo trabajaremos la presión, el pulso, la prensión, etc., adecuados.

- Motricidad gruesa. Presenta dificultades para el control preciso de las articulaciones superiores e inferiores. Necesita realizar ejercicios que estimulen su control motor y su sentido rítmico.

- Motricidad fina. Precisa de un seguimiento y desarrollo progresivo de actividades que ejerciten la coordinación óculo-manual y la precisión de sus movimientos.

- Esfuerzo/autorregulación. Uso de autoinstrucciones y de la mediación del adulto para aumentar los tiempos de dedicación en la tarea.

- Autonomía y hábitos. Necesita ayuda para la consecución de secuencias relacionadas.

Recibe apoyo directo de los maestros especialistas en pedagogía terapéutica y audición y lenguaje. Se prioriza apoyo dentro del aula y se realiza una coordinación con centros de rehabilitación y tratamiento a los que está asistiendo el alumno (Mitai, terapia asistida con caballos, fisioterapia, etc.) para definir pautas comunes de intervención, favoreciendo la inclusión educativa y la globalización de las medidas ofrecidas.

Los talleres de nuestro estudio se realizaron los viernes del segundo trimestre escolar del curso 2016/2017.

A continuación, explicamos el desarrollo de cada sesión en general y su aplicación con el alumno:

- Sesión 1. Presentamos la temática del taller proponiendo un debate sobre cuentos populares y tradicionales, otros contemporáneos, su opinión acerca de este tipo de literatura, etc. En todo momento prestaremos mucha atención a la adaptación de los periféricos para el alumno con discapacidad motora y a su destreza por el teclado de conceptos.

- Sesión 2. Debemos familiarizarnos con el dibujo y el significado de algunos pictogramas básicos. Para ello, enseñaremos la aplicación Pictosonidos, para asociar el significado a cada uno de ellos, y haremos juegos colectivos para asociar significante y significado de forma oral. 
- Sesión 3. Por parejas, usaremos esta herramienta para continuar con el trabajo de esta aplicación de forma más individualizada. Es en esta actividad en la que prestaremos especial atención al alumno con discapacidad motriz y le ayudaremos en las destrezas del teclado de conceptos y en la asimilación y pronunciación de los pictogramas correspondientes.

- Sesión 4. Antes de comenzar, debemos seguir un plan de actividades y propondremos a los alumnos crear una secuencia de las mismas. Para ello, recurriremos a la herramienta PictogramAgenda. Les indicaremos de cuántas sesiones dispondrán para hacer el trabajo por parejas en clase. Así, se organizarán semanalmente usando esta aplicación web.

- Sesión 5. Para mostrar todas las ideas que estamos expresando sobre las temáticas, los valores, la utilidad de los cuentos, etc., vamos a realizar un tablero de comunicación con la herramienta AraBoard que las sintetice.

- Sesión 6. Hemos profundizado mucho sobre la literatura como medio de expresión y vamos a ejemplificar todo lo aprendido redactando un cuento por parejas mediante la herramienta AraWord. Esta misma herramienta nos permite traducir en pictogramas las partes del texto que deseemos y facilitar la comprensión de los textos a los alumnos de esta edad, crear relatos originales, etc. Es la actividad que más destreza motriz requiere para escribir palabras por medio del teclado y convertirlas a pictogramas, seleccionar las partes que queremos que sean únicamente de texto, dotar de cohesión y organización al relato, etc. Haremos un seguimiento continuo para facilitar la escritura de palabras al alumno que presenta discapacidad motriz, proponiéndole un teclado de letras grandes, y otra sección de acciones básicas relacionadas con un teclado ordinario y flechas de ratón, para que pueda seleccionar las partes que necesite sin recurrir a este último.

- Sesión 7. Para exponer nuestro trabajo al resto de la clase, nos valdremos de la lámina impresa en la que aparezca el cuento que hemos redactado con AraWord y de un tablero de comunicación que complemente nuestra exposición, aclarando por qué hemos escogido ciertos personajes, con cuáles nos identificamos, escenarios, trama, qué valores trabaja el relato, etc., para facilitar el discurso cuando expongamos el trabajo por parejas. Igualmente, por parejas, elaboraremos un tablero de comunicación que refleje todas estas ideas. Esta actividad favorece el proceso de comunicación en niños de esta etapa, en la que aún están adquiriendo vocabulario y pautas para expresar sus ideas correctamente, lo que les facilitará un seguimiento en el discurso, les recordará alguna información relevante que tengan que exponer por medio de las secuencias de pictogramas que presenta el tablero, etc., siendo un medio de apoyo esencial para favorecer una vía de comunicación recíproca y eficaz entre el alumno con discapacidad motriz y los demás compañeros.

- Sesión 8. Expondrán oralmente los trabajos, sirviéndose del soporte en papel de los cuentos y de tableros de comunicación, además de su presentación al resto de los alumnos en la pizarra digital.

- Sesión 9. Encuadernaremos los relatos, junto con los tableros de comunicación correspondientes, para crear un gran libro de cuentos que refleje todos los aspectos tratados durante estos talleres, con la finalidad de poder recurrir a él, como medio de disfrute, el resto del curso, así como a la carpeta del ordenador del aula que recoja los mismos.

\section{A) Recursos empleados}

- Recursos metodológicos. Atenderemos a principios de intervención educativa, como la individualización, para atender las necesidades personales que presenten los alumnos y, concretamente, las del niño con discapacidad motriz, con la finalidad de acceder y usar los periféricos, la comprensión y el desarrollo de los materiales, etc. Para satisfacer los intereses y las necesidades de todos, también optaremos por el principio de socialización, proponiendo actividades en gran grupo (debates, diálogo, presentación de trabajos, etc.), fomentando especialmente al alumno de necesidades educativas sobre las actividades fonoarticulatorias, la adquisición de vocabulario y la consecución de consignas con ayuda de secuencias visuales y tableros de comunicación creados en los propios talleres. Además, en grupos pequeños y medianos (redactar relatos, crear tableros de comunicación, escuchar cuentos, etc.), reforzaremos al alumno con discapacidad motriz con la complejidad secuenciada de las actividades, la adaptación de los periféricos, los indicadores gráficos y audiovisuales, etc. La selección de la temática del taller (literatura infantil por medio de los cuentos) 
está directamente vinculada con sus intereses, actividades y valores de la vida diaria, por lo tanto, atendemos al principio de significatividad, así como al de aprender a aprender, ya que son ellos mismos los que construyen materiales didácticos a través de las herramientas TIC propuestas para plasmar los aprendizajes que vamos propiciando entre todos en clase, siempre de forma lúdica y favoreciendo el juego como principio de intervención educativa.

- Recursos personales. Los profesores actuarán como mediadores y guías durante el proceso de enseñanza-aprendizaje y como facilitadores del mismo para el alumno que presenta necesidades motrices, brindándoles las estrategias, las técnicas y los medios suficientes que describíamos en el apartado anterior, y resolviendo los inconvenientes que puedan ir encontrando durante la práctica de la propuesta, como hemos ido detallando a lo largo de cada una de las sesiones. Las actividades se presentan mediante talleres, por lo tanto, contaremos con personal de apoyo para realizarlas, es decir, con otros profesionales del centro, como los especialistas en audición y en lenguaje o el profesor de pedagogía terapéutica, con la finalidad de adaptar mejor algunos aprendizajes al niño con discapacidad motriz, así como con padres voluntarios, etc. Los niños serán los receptores de la propuesta y los constructores de su propio aprendizaje a lo largo del desarrollo de las actividades, prestando especial atención a la evolución del niño que presenta NEE.

- Recursos materiales. Disponemos de recursos materiales tangibles, como soportes en papel, reproductores de audio, ordenadores, periféricos adaptados, como el teclado de conceptos para el niño con necesidades motrices, útiles de escritura, etc. Materiales audiovisuales, como el software de ARASAAC, que nos permite realizar las actividades anteriormente descritas (AraWord, AraBoard, Cuentacuentos, Pictosonidos, etc.). Además, contaremos con el programa Overlay Maker, con el que se realizarán las plantillas necesarias para el uso del teclado de conceptos.

- Recursos ambientales. Las sesiones se desarrollarán preferentemente en el aula con los materiales audiovisuales y físicos que hemos mencionado anteriormente, recurriendo a la sala de informática para la realización de actividades que requieran el uso del ordenador de forma individual o grupal. La clase, aparte de contar con los periféricos y los softwares ya descritos para la aplicación de la propuesta, cuenta con la distribución espacial idónea para fomentar el desplazamiento autónomo del alumno con discapacidad motriz, estableciendo un orden estratégico de las mesas. Su ubicación es especial para salir a exponer a la pizarra digital o a otros espacios de trabajo de la clase, etc.

\subsubsection{Intervención en un niño con TDAH}

La propuesta pedagógica que se desarrolla a continuación se llevará a cabo mediante dos de las herramientas pedagógicas nombradas anteriormente: TDAH Trainer y, dentro del neurofeedback, Unobrain, puesto que, en comparación con PlayAttention, es un sistema creado por una empresa española y ha sido probado en numerosos centros educativos y hospitales de nuestro país (Unobrain, 2016). En referencia a esta última herramienta, accederemos a la cuenta premium gratuita para centros educativos. En el caso de TDAH Trainer, únicamente será necesaria su descarga en el correspondiente dispositivo electrónico donde se vaya a utilizar, abonando el coste que se requiere.

Los recursos necesarios para llevar a cabo la propuesta son una tablet, un ordenador, un casco de encefalografía (en concreto, el Neurosky Mindwave, compatible con el programa Unobrain [2016]).

El niño con el que trabajaremos tiene 8 años y está diagnosticado con TDAH. Presenta inatención, hiperactividad e impulsividad. Está integrado en un aula de $3 .^{\circ}$ de educación primaria que cuenta con un total de 20 alumnos con diferentes características, siendo este el único que presenta el trastorno. En cuanto a sus características personales, se trata de un niño que se distrae continuamente, presenta problemas de desobediencia, se precipita a la hora de contestar a las preguntas, tiene dificultades de organización, evita tareas con esfuerzo mental sostenido, comete muchos errores en las tareas escolares, tiene altos niveles de frustración y baja autoestima, etc.

Para lograr la inclusión de este niño, iniciaremos un entrenamiento cognitivo individualizado (en nuestro caso, este entrenamiento se llevó a cabo durante el primer semestre de 2017), con una duración de 25 semanas, es decir, un total de 5 meses, de lunes a viernes. Cada día se utilizará una herramienta, intercalándose a lo largo de los 5 días, y tendrá un horario 
planificado que se repetirá semanalmente. Las sesiones se realizarán en la primera o segunda hora de la mañana, puesto que es el momento de mayor concentración cerebral, y estarán distribuidas de acuerdo con las horas en las que el tutor tiene clase con el grupo en su totalidad, ya que será el encargado de guiar el entrenamiento del niño cada día. El tiempo que se dedicará al entrenamiento rondará los 15 minutos, aunque este tiempo puede variar, puesto que siempre se esperará a que el niño finalice el ejercicio que esté realizando y después se hará una reflexión sobre los errores y aciertos, apoyándonos en la retroalimentación que nos proporciona cada herramienta.

El docente será el coach o instructor de la terapia. Estará en todo momento con el alumno, motivándolo y fijándose en cada paso que da, por lo que tendrá que adjudicar al resto del grupo otro tipo de tareas que puedan realizar de manera individual, como ejercicios 0 lecturas. El instructor debe prestar especial atención a tres aspectos principales, que son:

- Fijarse en los ojos del sujeto. El neurofeedback nos proporciona información sobre la atención o inatención del alumno que esté realizando el entrenamiento, pero no nos informa en qué objeto está concentrándose. Por eso, es muy importante observar el trayecto de los ojos del niño para saber si realmente está siguiendo el juego.

- Instruir. Es importante que tanto el profesor como el alumno no hablen durante el juego, que no se muevan demasiado y que estén relajados, en la medida de lo posible, durante el entrenamiento para conseguir el mayor grado de concentración. Además, el coach debe orientar al usuario y motivarle con refuerzos positivos durante las pausas (Nascia, 2016).

- Feedback. Las dos herramientas nos proporcionan información sobre los progresos del usuario, que, en el caso del TDAH Trainer, se basa en los fallos y aciertos durante las jugadas, y en Unobrain, además de eso, en las frecuencias de las ondas cerebrales a través del casco de encefalografía. La labor del tutor será estar al tanto de esa retroalimentación e informar al niño sobre ello. Las actividades o los juegos que se utilizarán en el entrenamiento serán las que trae consigo cada herramienta. En TDAH Trainer activaremos el programa diario, de manera que cada día aparecerán automáticamente tres juegos adaptados a las características del niño, que deberemos completar en el registro de usuario. El sistema realizará un plan personalizado a través de los registros guardados en la base de datos e insistirá en aquellos en los que más errores se han cometido y que son, por tanto, las áreas más afectadas. Como esta herramienta no se utiliza todos los días, los ejercicios que nos haya planteado el programa y que aparezcan como no entregados se realizarán en la siguiente sesión. Los pasos que se desarrollarán en cada sesión de entrenamiento con cada una de las dos herramientas serán tres (Unobrain, 2016):

- Preparación (ambiente adecuado, poner al alumno los cascos, relajación, etc.).

- Realización del juego.

- Reflexión sobre los resultados del juego indicados en la retroalimentación del programa.

\subsubsection{Intervención en un niño con autismo}

Este programa de intervención está orientado a responder a las NEE que se derivan del propio trastorno autista y a conseguir la mejora de las destrezas necesarias para la comunicación, la interacción social y el desarrollo cognitivo. Antes de abordar de lleno la propuesta de implementación, tenemos que hacer hincapié en que el autismo es un concepto complejo y que no todos los niños con autismo presentan un patrón idéntico, por lo que hay que conocer de manera detallada sus características individuales. El alumno en el cual se llevará a cabo la intervención educativa pertenece a $2 .{ }^{\circ}$ de educación primaria. Tiene 7 años y presenta las características propias de este trastorno del desarrollo, teniendo especial dificultad en la reciprocidad social y emocional, en la comunicación y el lenguaje, en la comprensión de su entorno y en una excesiva fijación en las rutinas.

La intervención se llevará a cabo durante el primer trimestre escolar, 2 días a la semana (lunes y miércoles) en módulos de 45 minutos diarios que se corresponderán con el área de Lengua Castellana y Literatura. Todas ellas se llevarán a cabo de 0.9:00 a 09:45 h. Durante estas sesiones se empleará la herramienta TIC Día a Día para favorecer el desarrollo de las áreas donde el alumno presenta mayor dificultad. Para poder atender de manera más individualizada al 
alumno durante la intervención, el maestro de apoyo acudirá al aula del alumno para trabajar con las herramientas durante dichas sesiones y para hacer un seguimiento coordinado con el tutor sobre los resultados que se vayan obteniendo. La idea es que el alumno aprenda a utilizar las herramientas con autonomía y estas le sean de utilidad para su día a día. El dispositivo que se empleará será una tablet, debido a su comodidad.

Para la implementación de la herramienta se seguirán una serie de pautas, de manera que se produzca un mejor aprovechamiento de la actividad educativa. Algunas de esas pautas serán:

- Partir de los intereses del alumno.

- Aprovechar rutinas cotidianas.

- Prediseñar las situaciones.

- Emplear ayudas para provocar actos comunicativos.

- Ofrecer al alumno la oportunidad de elegir, fomentando la toma de decisiones.

- Utilizar un lenguaje sencillo.

- Aprendizaje sin error (se le facilitarán al alumno los apoyos necesarios para que realice la tarea de manera satisfactoria).

- Establecer rutinas.

- Evitar las distracciones.

Es esencial ayudar a estos alumnos a anticipar actividades y acontecimientos diarios. Para ello emplearemos la herramienta Día a Día, que utilizaremos como diario, además de como agenda. Los objetivos que buscamos con la implementación de esta herramienta son:

- Planificar rutinas y acontecimientos.

- Expresar hechos o sucesos del pasado, del presente 0 del futuro.

- Secuenciar las actividades que permitan detallar los pasos de las tareas que se van a realizar.

- Fomentar un clima educativo relajado con la finalidad de favorecer conductas positivas, evitando el desconcierto y las posibles conductas disruptivas.

A tenor del conocimiento de la herramienta, y respondiendo a las necesidades educativas de nuestro alumno, las actividades que creemos programables e idóneas para una correcta actuación son las siguientes:
- Utilización de la herramienta como agenda con la función de previsión, de tal modo que le sirva al alumno como método de anticipación del futuro y le permita organizar y secuenciar las acciones que va a realizar siguiendo un plan sencillo, respondiendo de esta forma a las dificultades organizativas que presenta el alumno. Además, esta herramienta permitirá la intervención ante conductas desconcertantes, cuando se produzca la sensación de desconexión y en momentos de ansiedad. Las imágenes o pictogramas serán interpretados y asociados sin dificultad.

- Implementación de la actividad para preparar y organizar acontecimientos importantes que no se den en el aula. En este caso, para preparar el fin de semana, su cumpleaños y la Navidad, es decir, momentos en los que se pueden producir situaciones desconcertantes e imprevisibles, ya que esos periodos de tiempo están menos estructurados, hay menos rutinas y hay posibilidad de interacciones con personas no habituales. Aquí es útil el recurso del vídeo que nos ofrece la herramienta, el cual permitirá visualizar los eventos.

- Uso de la aplicación como herramienta de recordatorio para facilitar y fomentar la comunicación, de manera que se vinculen los diferentes acontecimientos a situaciones de comunicación.

Un aspecto claro que hay que tener en cuenta en la implementación de esta herramienta es su aplicación y su uso imprescindible durante todo el día, y no solo en el ámbito educativo, sino también fuera de él, utilizándose del modo en que hemos comentado (organización de rutinas y eventos, modificaciones que se puedan dar durante el día, recordatorio de actividades, etc.). En definitiva, con el empleo de esta herramienta y la implementación de estas actividades, buscamos una mejora de la comprensión del entorno del alumno, la motivación ante el aprendizaje y la contribución a la ordenación de su mundo.

\section{CONCLUSIONES}

La inclusión de alumnos con NEE es un concepto complejo que requiere de mayor investigación. Los centros educativos deben ofrecer una respuesta de calidad al alumnado con NEE y garantizar su inclusión. Este hecho marcó la motivación principal para 
la realización de este trabajo. Los objetivos principales se han cumplido. Se han encontrado y descrito herramientas y aplicaciones TIC útiles para la enseñanza de este tipo de alumnado, en concreto para los estudiantes con discapacidad motriz, con autismo y con TDAH.

Tras haber realizado este trabajo, se extraen varias conclusiones:

- Las TIC son una propuesta con grandes posibilidades para las personas con discapacidad motriz, con TEA y con TDAH en el ámbito educativo. Los resultados de este estudio concuerdan con Pérez de la Maza (2000) en cuanto a que las TIC ofrecen un entorno y una situación controlable, presentan una estimulación multisensorial, su capacidad de motivación y refuerzo es alta (favorecen la atención y disminuyen la frustración ante los errores), posibilitan el trabajo autónomo y el desarrollo de las capacidades de autocontrol y se adaptan a las características personales, favoreciendo la integración. Son un elemento de aprendizaje activo, versátil, flexible y adaptable.

- La formación del profesorado en las TIC y en las necesidades educativas del alumnado es fundamental para garantizar que el proceso de enseñanzaaprendizaje sea efectivo.

- Debe existir coordinación entre todas las personas que intervienen en la acción educativa del alumno.

- Las TIC deben entenderse como un elemento de ayuda en el aula y no como un sustitutivo del profesor. Hay que impedir que el alumno se vuelva dependiente de ellas y no realice otro tipo de actividades.

- Hay que tener claros los objetivos que se quieren conseguir y conocer las características de las personas con las que se va a trabajar. Dada la heterogeneidad de los alumnos con NEE, no hay un caso igual a otro. Las herramientas y aplicaciones TIC que se seleccionen deben tener en cuenta estos aspectos.

- La presencia de softwares, aplicaciones y fundaciones destinadas a estas personas crece día a día. En la línea de la integración curricular buscaremos aquel material informático que sirva especialmente para el aprendizaje de aquellas áreas en las que suelen presentar mayor dificultad, como son las habilidades sociales, comunicativas, relaciones interpersonales, imaginación, reconocimiento de emociones.

\section{La inclusión de alumnos con NEE es un concepto complejo que requiere de mayor investigación. Los centros educativos deben ofrecer una respuesta de calidad al alumnado con NEE y garantizar su inclusión}

- Las TIC están cobrando fuerza en este ámbito. Muestra de ello son las conferencias, las charlas, los congresos o las jornadas destinadas a conocer las últimas novedades en dispositivos tecnológicos, útiles para estos alumnos, así como a compartir las experiencias llevadas a cabo, todo ello con la finalidad de establecer así posibles mejoras para el futuro.

Aunque las TIC están en auge dentro del campo educativo, lo cierto es que aún queda mucho camino por recorrer para que los centros las incorporen como recurso habitual en el alumnado con NEE. Los motivos son variados, desde la falta de formación del profesorado respecto a las TIC y a la realidad de este alumnado, hasta la falta de recursos y de medios para poder emplearlas de manera eficiente.

La relevancia y la actualidad de la temática de este estudio invitan a seguir investigando sobre él. El trabajo futuro más inmediato sería llevar a cabo la propuesta en los centros educativos. Los resultados que se obtuvieran permitirían obtener unas conclusiones útiles para extender la propuesta a otros centros educativos o plantear mejoras para trabajos futuros. La evidencia de que las TIC, durante el proceso de enseñanza- aprendizaje, contribuyen a la integración y a la futura inserción laboral se observa en que actualmente hay empresas del sector de la informática, como Microsoft, que cuentan con personas con NEE en su plantilla, destacando su capacidad y talento en aspectos como la memoria, la concentración, la atención al detalle o la mínima tolerancia al error. En definitiva, la sociedad y la ciencia deben continuar haciendo hincapié y buscando nuevas soluciones para subsanar los obstáculos de los alumnos con necesidades educativas especiales. 


\section{BIBLIOGRAFÍA}

Aguado, A. y Alcedo, M. ${ }^{a}$ Á. [1991]: Apuntes de psicología de la rehabilitación de las discapacidades físicas, Universidad de Oviedo: Departamento de Psicología.

Aguilar, L. Á. [1991]: «El informe Warnock (1978)», Cuadernos de Pedagogía, 197, págs. 62-64.

Ainscow, M. [1995]: Necesidades especiales en el aula, Madrid: Narcea.

Alexander, M. A. y Bauer, R. E. [1988]: «Cerebral palsy», en V. B. Van Hasselt, P. S. Strain y M. Hersen (eds.), Handbook of developmental and physical disabilities, New York: Pergamon Press, págs. 227-246.

Álvarez, F. [2011]: Accesibilidad universal y diseño para todos, Madrid: Fundación ONCE.

APA [1968]: Diagnostic and statistical manual of mental disorders (DSM-II), 2. ${ }^{\text {a }}$ ed., Washington DC: Author.

[1980]: Diagnostic and statistical manual of mental disorders (DSM-III), 3. ${ }^{\text {a }}$ ed.,Washington DC: Author.

[1987]: Diagnostic and statistical manual of mental disorders (DSM-III-R), 3. a ed. revisada, Washington DC: Author.

[2000]: Diagnostic and statistical manual of mental disorders (DSM-IV), Washington DC: Author. DOI 10.1176/appi.books. 9780890423349.

Blanco, R. [1990]: «La atención a la diversidad en el aula y las adaptaciones del currículo», en Á. Marchesi, C. Coll y J. Palacios, Desarrollo psicológico y educación, III: necesidades educativas especiales y aprendizaje escolar, Madrid: Alianza Editorial, págs. 411-438.

Cabero, J. y Córdoba, M. [2009]: «Inclusión educativa: inclusión digital», Revista de Educación Inclusiva, 2 (1), págs. 61-77. Disponible en: http://rabida. uhu.es/dspace/bitstream/handle/10272/11296/Inclusion_educativa.pdf?sequence=2 [Consultado: 26 de enero de 2017].

Cabero, J.; Córdoba, M. y Fernández J. M. ${ }^{a}$ (coords.) [2007]: Las TIC para la igualdad, Sevilla: MAD Eduforma.

Comité Español de Representantes de Personas con Discapacidad (CERMI) [2015]: Tecnologías educati- vas accesibles. Guía de recursos, Gobierno de España: Ministerio de Educación, Cultura y Deporte.

Cook, A. y Polgar, J. [2000]: Assistive technologies: principles and practice, New York: Mosby-Year Book Inc.

Cruz, J. [2012]: «Qué sabemos del neurofeedback para el tratamiento del TDAH», Tratamiento Educativo del TDAH. Disponible en: https://educaciontdah. wordpress.com/2012/11/07/que-sabemos-sobre-elneurofeedback-para-el-tratamiento-del-tdah/ [Consultado: 6 de julio de 2016].

Departamento de Educación del Gobierno de Navarra [2001]: Entender y atender al alumnado con déficit de atención e hiperactividad (TDAH) en las aulas. Guía para el profesorado, Navarra: Fondo de Publicaciones del Gobierno de Navarra.

Echeita, G. y Navarro, D. [2014]: «Educación inclusiva y desarrollo sostenible: una llamada urgente a pensarlas juntas», Edetania: Estudios y Propuestas Socio-Educativas, 46, págs. 141-162.

Gaitán, A. [2015]: «¿Qué es neurofeedback?», YouTube. Disponible en: https://www.youtube.com/watch?v=wi bCjUaimgY [Consultado: 6 de julio de 2016].

Gallego, J. L. y Rodríguez, A. [2012]: «¿Cómo aprenden ahora los estudiantes de Magisterio a atender a la diversidad de su alumnado?», Profesorado, $R e$ vista de Currículum y Formación de Profesorado, 16 (2), págs. 249-294.

García Ponce, F. J. (dir.) [2011]: «Accesibilidad, TIC y educación», Serie Informes, 17, España: Secretaría General Técnica.

García Gómez, S. y García Pastor, C. [5-7 de septiembre de 2007]: «Del interés por atender a la diversidad del alumnado a la necesidad de reflexionar sobre las propias prácticas de enseñanza. Una experiencia de formación permanente del profesorado», comunicación presentada en el I Congreso Internacional Nuevas Tendencias en la Formación Permanente del Profesorado, Barcelona (España).

García Pastor, C. y Marchena Gómez, R. [2013]: «La inclusión educativa en la práctica», Siglo Cero: $R e$ vista Española sobre Discapacidad Intelectual, 44 (2), págs. 6-25. 
Gimeno, J. [2000]: «La construcción del discurso acerca de la diversidad y sus prácticas», en AA. VV., Atención a la diversidad, Barcelona: Graó, págs. 11-35.

Hartlage, L. C. [1983]: Neuropsychological assessment techniques, New York: Whiley.

Hervás, C. y Toledo, P. [2007]: «Las tecnologías como apoyo a la diversidad del alumnado», en J. Cabero (coord.), Tecnologías educativas, Madrid: McGrawHill, págs. 236-248.

Hodges, R. [s. f.]: Additude (ADHD video games: building better focus through fun alternative treatments). Disponible en: http://www.additudemag.com/adhd/ article/798.html [Consultado: 6 de julio de 2016].

IMSERSO [2003]: I Plan Nacional de Accesibilidad 2004-2012. Por un Nuevo Paradigma, el «Diseño para Todos», hacia la Plena Igualdad de Oportunidades, Ministerio de Trabajo y Asuntos Sociales, Secretaría General de Asuntos Sociales. Disponible en: https://www.sidar.org/recur/direc/legis/ipna2004_2012. pdf [Consultado: 26 de enero de 2017].

Inclusión Educativa [2006-2016]: http://www.inclusioneducativa.org/content/documents/MARCO_GENERAL_DE_LA_El.pdf [Consultado: 26 de enero de 2017].

INTEF [2015]: Clasificación de alumnado con necesidades educativas específicas, Ministerio de Educación, Cultura y Deporte. Disponible en: http://formacion.educalab.es/pluginfile.php/41154/ mod_imscp/content/1/Ficha_3.3.pdf [Consultado: 26/01/2017].

Kano, M. [2013]: «Tecnología y discapacidad: una mirada pedagógica», Revista.unam.mx, 14 (12). Disponible en: http://www.revista.unam.mx/vol.14/ num12/art53/ [Consultado: 6 de julio de 2016].

León, O. y Montero, I. [2015]: Métodos de investigación en psicología y educación, 4. ${ }^{a}$ ed., Madrid: McGraw-Hill.

Ley orgánica 2/2006, de 3 de mayo, de educación (BOE núm. 106, de 4 de mayo de 2006, págs. 17.158-17.207).

Luna, M. R. [2013]: «Tecnología y discapacidad: una mirada pedagógica», Revista Digital Universitaria, 14 (12), págs. 1-18.

Mae, S. [2011]: «Condicionamiento operante», Explorable. Disponible en: https://explorable.co m/es/condicionamiento-operante [Consultado: 6 de julio de 2016].
Nascia [2016]: PlayAttention. Disponible en: http://playattention.es/ [Consultado: 6 de julio de 2016].

Negre, F. [2003]: «Tic y discapacidad: implicaciones del proceso de tecnificación en la práctica educativa, en la formación docente y en la sociedad», Pixel-Bit: Revista de Medios y Educación, 21, págs. 5-14. Disponible en: http://www.redalyc.org/ pdf/368/36802101.pdf [Consultado: 6 de julio de 2016].

Ortega-Tudela, J. M. y Gómez-Ariza, C. [2007]: «Nuevas tecnologías y aprendizaje matemático en niños con síndrome de Down: generalización para la autonomía», Pixel-Bit: Revista de medios y educación, 29, págs. 59-72.

Parrilla, A. [2002]: «Acerca del origen y sentido de la educación inclusiva», Revista de Educación, 327, págs. 11-29.

Pérez de la Maza, L. [2000]: «Programa de Estructuración Ambiental por Ordenador para personas con trastornos del espectro autista: PEAPO», en F. J. Soto Pérez y J. Rodríguez Vázquez (coords.), Las nuevas tecnologías en la respuesta educativa a la diversidad, Murcia: Selegráfica, SL, págs. 255-258.

Real Decreto 1494/2007, de 12 de noviembre, por el que se aprueba el Reglamento sobre las condiciones básicas para el acceso de las personas con discapacidad a las tecnologías, productos y servicios relacionados con la sociedad de la información y medios de comunicación social (BOE núm. 279, de 21 de noviembre de 2007, págs. 47.567-47.572).

Santos, A. [2012]: El uso de las nuevas tecnologías para alumnos con necesidades educativas especificas, Barcelona: Bubok Publisihing, SL.

UNESCO [7-10 de junio de 1994]: Conferencia Mundial sobre Necesidades Educativas Especiales: Acceso y Calidad, Salamanca (España). Disponible en: http:// unesdoc.unesco.org/images/0011/001107/110753so. pdf [Consultado: 6 de julio de 2016].

Universidad Internacional de Valencia [s. f.]: Trabajando la inclusión educativa: la inclusión de los niños con necesidades educativas especiales (NEE). Disponible en: http://www.viu.es/caracteristicas-buenas -practicas-para-la-educacion-inclusiva/ [Consultado: 6 de julio de 2016]. 
Unobrain [2016]: http://www.unobrain.com/ [Consultado:

6 de Julio de 2016].

Warnock, M. [1981]: Meeting special educational needs, London: Her Britannic Majesty's Stationary Office.
Waterhouse, L.; Wing, L.; Sptzer, R. y Siegel, B. [1992]: «Pervasive developmental disorders: from DSM-III to DSM-III-R», Journal of Autism Development Disorder, 22 (4), págs. 525-549.

\section{PUBLICIDAD}

La UDIMA, desde su condición de universidad a distancia, ha diseñado el programa formativo del Máster en Educación y Nuevas Tecnologías, con el que se pretende formar a profesores, investigadores y educadores para que conozcan, asuman y adapten las nuevas tecnologías a sus necesidades docentes e investigadoras.

Este máster oficial [60 créditos ECTS] se inicia en febrero y octubre de cada año y su duración normal es de 12 meses.

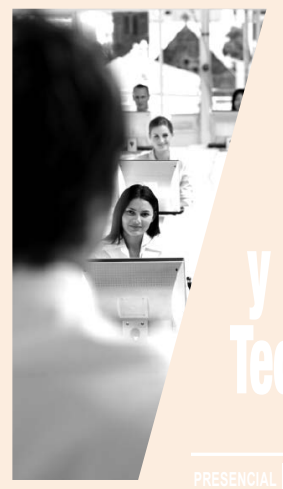

DIRIGIDO A: Titulados universitarios de las distintas ramas del conocimiento que deseen especializarse en el correcto desempeño de las funciones de un experto en educación y nuevas tecnologías. No exige experiencia previa en el ámbito educativo.

OBJETIVOS: Capacitar a profesores, investigadores y educadores en el conocimiento y empleo de las nuevas tecnologías de la comunicación y la información, así como de los nuevos modelos formativos e-learning y $b$-learning, en beneficio de las acciones formativas en los nuevos contextos educativos. Al mismo tiempo, trata de profundizar en el conocimiento de las posibilidades que ofrecen las tecnologías actuales y emergentes para encontrar nuevas formas de obtención y manejo de información en ámbitos educativos. 